\title{
DNA methylation analysis on purified neurons and glia dissects age and Alzheimer's disease-specific changes in the human cortex
}

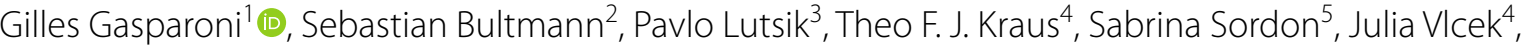 \\ Vanessa Dietinger ${ }^{4}$, Martina Steinmaurer ${ }^{4}$, Melanie Haider ${ }^{4}$, Christopher B. Mulholland ${ }^{2}$, Thomas Arzberger ${ }^{4}$, \\ Sigrun Roeber ${ }^{4}$, Matthias Riemenschneider ${ }^{5}$, Hans A. Kretzschmar ${ }^{4}$, Armin Giese ${ }^{4}$, Heinrich Leonhardt ${ }^{2}$ \\ and Jörn Walter ${ }^{1 *}$
}

\begin{abstract}
Background: Epigenome-wide association studies (EWAS) based on human brain samples allow a deep and direct understanding of epigenetic dysregulation in Alzheimer's disease (AD). However, strong variation of cell-type proportions across brain tissue samples represents a significant source of data noise. Here, we report the first EWAS based on sorted neuronal and non-neuronal (mostly glia) nuclei from postmortem human brain tissues.

Results: We show that cell sorting strongly enhances the robust detection of disease-related DNA methylation changes even in a relatively small cohort. We identify numerous genes with cell-type-specific methylation signatures and document differential methylation dynamics associated with aging specifically in neurons such as CLU, SYNJ2 and NCOR2 or in glia RAI1,CXXC5 and INPP5A. Further, we found neuron or glia-specific associations with AD Braak stage progression at genes such as MCF2L, ANK1, MAP2, LRRC8B, STK32C and S100B. A comparison of our study with previous tissue-based EWAS validates multiple AD-associated DNA methylation signals and additionally specifies their origin to neuron, e.g., HOXA3 or glia (ANK1). In a meta-analysis, we reveal two novel previously unrecognized methylation changes at the key AD risk genes APP and ADAM17.
\end{abstract}

Conclusions: Our data highlight the complex interplay between disease, age and cell-type-specific methylation changes in AD risk genes thus offering new perspectives for the validation and interpretation of large EWAS results.

Keywords: DNA methylation, Epigenetics, Alzheimer's disease, Neurodegeneration, Aging, Cell sorting, Neuron, Glia, Brain, EWAS

\section{Background}

Alzheimer's disease (AD) is a fatal neurodegenerative disorder and the most common form of age-related dementia. The majority of AD cases are diagnosed as late-onset $\mathrm{AD}$ but its aetiology is thought to start much earlier in life and to slowly progress until first symptoms emerge [53]. At the cellular level, AD can be characterized by the appearance and extent of (i) extracellular

\footnotetext{
*Correspondence: j.walter@mx.uni-saarland.de

${ }^{1}$ Department of Genetics, University of Saarland (UdS), Campus,

66123 Saarbrücken, Germany

Full list of author information is available at the end of the article
}

plaques from accumulations of insoluble amyloid beta filaments, (ii) intracellular neurofibrillary tangles of hyperphosphorylated tau $[25,115,117]$ and (iii) neuroinflammation. According to the amyloid cascade hypothesis [39], AD results from neurotoxic amyloid beta plaques which form from excess of APP protein filaments derived by sequential proteolytic cleavage by $\beta$ - or $\gamma$-secretases $[15,103]$. Neuropathologically, AD is classified according to spread of disease marks across the brain regions (Braak stages) [13]. Despite intense research, molecular causes for AD and the relationship to normal aging are not well understood. Only a minority of $\mathrm{AD}$ cases can be explained by mutations in the genes APP, 
PSEN1 and PSEN2 [16, 22]. Recently, several studies suggest neuroepigenetic mechanisms to be involved in $\mathrm{AD}$ etiology suggesting that the sum of acquired epigenetic alterations over lifespan could play a role [68, 88, 89]. In the central nervous system (CNS), these processes are indispensable for cells to execute complex functions such as learning and memory, but are also involved in the context of aging and neuropathologic processes $[2,10,23$, 116]. To date, DNA methylation at cytosines $(5-\mathrm{mC})$ in a CpG sequence context is the best understood and most extensively studied epigenetic mark $[75,76]$ which can be target for further modifications from 5-mC to 5-hydroxymethylcytosine, to 5-formylcytosine to 5-carboxymethylcytosine by the family of Tet enzymes [124]. In particular, 5 -hmC the most prominent oxidized form of cytosine methylation is identified in cells of the CNS [64] and recent studies in the brain reported altered proportions upon aging and in disease $[5,19,26,43,63,70,98,136]$.

Two recent large EWAS based on human brain tissue reported Braak stage-associated methylation changes at several genes such as ANK1,RPL13, CDH23, HOXA3 and $B I N 1$ [27, 82]. Notably, methylation changes at the APP gene locus have so far only been shown for individual $A D$ cases $[52,129,137]$ while a larger study could not confirm this observation [6]. One main obstacle is that in the cortex cell-type composition changes upon aging and/ or disease progression [122]. This heterogeneity in tissue composition constitutes a major source of noise in epigenetic profiles and compromises a clean distinction of age, cell-type and disease-related changes across samples. Several bioinformatic approaches were developed to address this problem $[47,48,97,104]$. However, there is an ongoing dispute concerning their proper usability $[105,144]$. In our study, we circumvent this problem by profiling cells separated into neuronal- and glia fractions of cortices from 31 healthy donors and AD patients with well-defined Braak stages. A comparison of cell sorting and bulk tissue-based screens reveals that cell-type purification efficiently reduces confounding noise generated by variable cell composition and enhances the detection of disease-related changes. Therefore, we detect a substantial number of Braak stage-associated markers previously only found in much larger datasets of total brain tissue. In addition, cell sorting allows assignment of identified signals to cell-type origin and reveals that next to neurons also glia cells experience strong epigenetic alterations upon $\mathrm{AD}$ progression.

\section{Results}

\section{Cellular heterogeneity in brain tissue undermines} the association analysis for Braak stage

The aim of this study is to address DNA methylation changes in the human brain that are associated with aging and/or with increasing Braak stages. Before starting our cell sorting approach, we performed an initial DNA methylation screen on unsorted 128 postmortem bulk brain samples (63 frontal (FC) and 65 temporal cortex (TC) samples) derived from 52 healthy controls (CTRL) and 76 AD donors (Additional file 2: Tables S1S2) using Illumina's HumanMethylation $450 \mathrm{k}$ bead array platform. Following state of the art data processing [72] (see "Methods" section), we obtained data for more than 460,000 CpGs per sample. To calculate the association between DNA methylation and Braak stage progression or aging, we applied multiple linear regression models thereby correcting for sex, age and batch effects (see principal component analysis; Additional file 1: Fig. S1k, l). In addition, we calculated for each sample the neuronal content following the method described by Houseman et al. [47]. We separately analyzed FC and TC samples to exclude brain region effects (Additional file 1: Fig. S1a-d) (Additional file 2: Tables S3-S6). With respect to aging, we identified only six differentially methylated CpGs (DMCGs) overlapping between FC and TC when comparing the two top 1000 ranked CpGs (Additional file 1: Fig. S1g) while 171 were common among the top 1000 Braak stage-associated CpG sets (Additional file 1: Fig. S1h). Also, only little overlap was observed for aging and Braak-DMCGs within FC or TC (Additional file 1: Fig. S1e, f). We used the top 1000 top ranking Braak-DMCGs in a cluster analysis, but the samples did not clearly differentiate for diagnosis (Additional file 1: Fig. S1i) and the observed changes were between low and high Braak stages were mostly low (Additional file 1: Fig. S1j) suggesting a limited discriminative power of the analysis. In addition, none of our 200 top ranking CpGs from FC or TC showed overlap with a recently published large ADEWAS also based on brain tissue material [82]. A possible explanation for this could be that our cohort was smaller compared to the published EWAS. Alternatively, we reasoned that $5-\mathrm{mC}$ profiles might strongly differ between populations (cohorts) or show variable grades of heterogeneity in individual cell-type composition. To overcome this problem, we decided to proceed with a reduced number of samples for which we physically separated neuronal and non-neuronal cell-types.

\section{Cell separation identifies a broad range of cell-type-specific methylation signatures}

We performed NeuN immunolabeling followed by FACS separation $[3,51,55,80,93,100,128]$ to obtain neuronal (NeuN-positive, referred to as neurons) and nonneuronal nuclei (NeuN-negative, referred to as glia) from 31 human postmortem occipital cortex samples. From this, we generated 62 epigenome-wide cell-typespecific profiles (Additional file 2: Tables S1-S2) on an 
(See figure on next page.)

Fig. 1 Experimental setup and cell-type-specific DNA methylation signatures. a General work flow scheme for neuron and glia cell-type separation and DNA methylation profiling. $\mathbf{b}$ Cluster analysis on complete data shows full separation of neuron and glia samples. $\mathbf{c}$ Volcano plot for identification of 57,908 cell-type-specific CpGs (ct-DMCGs, dark red) in sorted CTRLs. d Genomic distribution of ct-DMCGs that are hypo- or hypermethylated in neurons. CpGs are classified in respect of hypo-or hypermethylation in neurons compared to glia. e Relative distribution of ct-DMCGs in relation to array design. $\mathbf{f}$ NGS-based validation for exemplary ct-DMCGs in a subset of neuron and glia samples. Columns represent methylation levels of cytosines at CpGs (upper panels) or CpAs (lower panels). Rows are samples ordered by similarity. Black triangles mark CpGs that are present on the 450k array. NC/GC: neuron/glia controls, N3-N6/G3-G6: neuron/glia Braak stages III-VI. g Similarity of neuronal methylation profiles (CTRLs only) for our own study (dataset 1) and data from Guintivano et al [35] (dataset 2). $\mathbf{h}$ Overlap of ct-DMCGs as defined by datasets 1 and 2 , respectively

Illumina 450k methylation array platform (for general work flow, processing and quality checks see "Methods" section and Fig. 1a). Cluster analysis revealed a clear overall separation of neuronal and glia samples (Fig. 1b). To systematically define cell-type-specific methylation sites (ct-DMCGs), we compared neuron and glia samples (controls only) by a two-sided $t$ test and filtered for autosomal CpGs with a significant $p$ value (Bonferroni corrected) and methylation difference of at least 20\% (Fig. 1c, Additional file 2: Table S7). In total, we identified 57,908 ct-DMCGs (approx. $12 \%$ of all sites) distributed across 11,279 genes, many of which are known to be differentially expressed in neurons and glia cells such as SYNPO [96] (cg06732545, $p=7.09 * 10^{-29}$, rank 82), FOXP1 [125] (cg21836903, $p=4.48 * 10^{-27}$, rank 329) and MBP [38] (cg24446429, $\left.p=3.28 * 10^{-22}\right)$. A bit more than half (54\%) of all ct-DMCGs were hypermethylated in neurons (Fig. 1d). Most of the ct-DMCGs were located at gene body and promoter regions and only very few in intergenic regions (Fig. 1d). Compared to the array design, we observed more hypomethylated ct-DMCGs at the gene body while hypermethylated ct-DMCGs were enriched at gene promoters and exon 1 regions (Fig. 1e). A GO enrichment analysis revealed mostly neurological process such as 'neuron projection morphogenesis', 'modulation of synaptic transmission' and 'regulation of neurotransmitter levels' (Additional file 2: Table S8). We also validated a larger set of differential loci using deep bisulfite amplicon sequencing (Fig. 1f). We found a high concordance between 450k array data and NGS data $\left(R^{2}=0.912\right.$; Additional file 1: Fig. S2b, Additional file 2: Table S9). In line with previous findings [75], we detected pronounced non-CpG methylation levels mostly at $\mathrm{CpA}$ dyads for neurons and to much a lesser extent for glia (Fig. 1f). In addition, we validated cell-type-specific expression at the protein level using immunohistochemical staining with specific antibodies against SORL1 and FOXP1, respectively (Additional file 1: Fig. S2c, Additional file 2: Table S10). Taken together we confirm a successful and clear separation of neuronal and glia cell fractions from fresh frozen brain tissue.
We next compared our results to a recent study that also applied NeuN-based separation of human neuron and glia cells [35]. From this dataset, we selected all 23 healthy Caucasian samples (Additional file 2: Table S2). The correlation between our and the Guintivano et al. study was very good $\left(R^{2}>0.99\right)$ both for the neuronal and glia methylation profiles (Fig. 1g, Additional file 1: Fig. S2d). Moreover, the majority of neuron to glia differences were highly similar (Additional file 1: Fig. S2e) as clearly demonstrated by the concordant placement in a principal component analysis (Additional file 1: Fig. S2a). About 48,220 (88.3\%) ct-DMCGs overlapped with those identified in our own data (Fig. 1h). We would like so stress that the Guintivano cohort was derived from frontal cortex while our samples were from occipital cortex. So we wondered if NeuN-sorted samples from different brain regions might exhibit distinct methylation signatures. To follow this question we performed a correlation analysis on a subset of healthy control samples from our cohort (occipital cortex) and from the Guintivano study that are matched for sex, age and cell-type $(n=5)$. Notably, we observe the same very high degree of correlation within and across cohorts (Additional file 2: Table S11), indicating that $\mathrm{NeuN}$-sorted methylation profiles from both regions are comparable. Further, in a PCA analysis, they clustered together independent of cohort (data not shown). Given this high agreement, we conclude that NeuN-based cell separation from human cortical postmortem samples is a robust and reproducible approach, even across brain regions and cohorts. We therefore felt confident to include the 23 samples from the Guintivano study as additional controls in our subsequent analyses. Other samples from this study including non-Caucasian controls were not used.

\section{Neuron and glia methylomes change distinctly upon aging} To analyze age-associated DNA methylation changes in both cell fractions (Table 1) we applied multiple linear regression models separately for the neuron and glia samples correcting for the confounding variables sex and technical batch effects (see "Methods" section). While we 


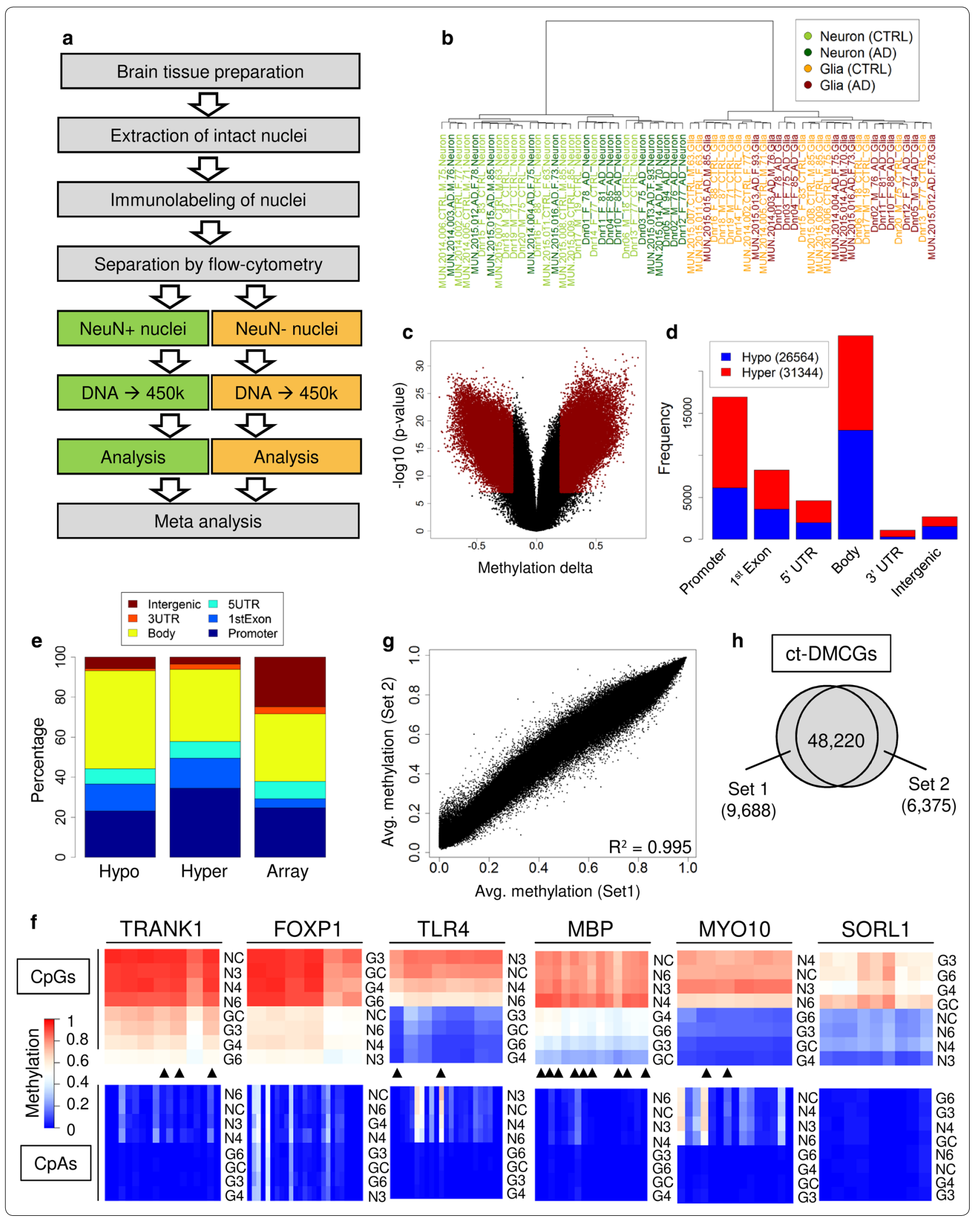


Table 1 Top 25 aging-DMCGs identified in the meta-analysis

\begin{tabular}{|c|c|c|c|c|c|c|c|c|c|}
\hline Rank & $\begin{array}{l}P \text { value } \\
\text { (meta- } \\
\text { analysis) }\end{array}$ & $P$ value (neuron) & $P$ value (glia) & TargetID & Chr & Position & Gene & Region & FDR \\
\hline 1 & 4.34E-27 & $6.58 \mathrm{E}-09$ & $1.00 \mathrm{E}-20$ & $\operatorname{cg} 13327545$ & 10 & 22623548 & & & $2.0763 E-21$ \\
\hline 2 & $9.38 \mathrm{E}-26$ & $5.55 E-10$ & $2.69 \mathrm{E}-18$ & $\operatorname{cg} 16867657$ & 6 & 11044877 & ELOVL2 & TSS1500 & $2.2438 \mathrm{E}-20$ \\
\hline 3 & $2.53 \mathrm{E}-25$ & 8.99E-09 & $4.56 \mathrm{E}-19$ & cg20224218 & 9 & 129261375 & FAM125B & Body & $4.0346 \mathrm{E}-20$ \\
\hline 4 & $4.38 \mathrm{E}-25$ & $5.03 E-06$ & $1.42 \mathrm{E}-21$ & cg10804656 & 10 & 22623460 & & & $5.2387 \mathrm{E}-20$ \\
\hline 5 & $6.46 \mathrm{E}-25$ & $9.09 \mathrm{E}-14$ & $1.17 \mathrm{E}-13$ & cg14919554 & 5 & 43018629 & & & $6.1811 \mathrm{E}-20$ \\
\hline 6 & $8.12 E-25$ & $2.95 \mathrm{E}-17$ & $4.54 \mathrm{E}-10$ & $\operatorname{cg} 02426178$ & 19 & 10747142 & SLC44A2 & Body & $6.4746 \mathrm{E}-20$ \\
\hline 7 & 1.65E-24 & $5.49 \mathrm{E}-16$ & $5.01 \mathrm{E}-11$ & cg03984866 & 4 & 8161776 & ABLIM2 & TSS1500 & $1.0465 \mathrm{E}-19$ \\
\hline 8 & $1.75 \mathrm{E}-24$ & $1.52 \mathrm{E}-09$ & $1.92 \mathrm{E}-17$ & cg10906284 & 12 & 63544430 & AVPR1A & 1stExon & $1.0465 \mathrm{E}-19$ \\
\hline 9 & $2.38 \mathrm{E}-24$ & $2.13 E-06$ & $1.88 \mathrm{E}-20$ & $\operatorname{cg} 17117277$ & 19 & 3822126 & ZFR2 & Body & $1.2651 \mathrm{E}-19$ \\
\hline 10 & $5.41 \mathrm{E}-24$ & $2.75 \mathrm{E}-08$ & $3.36 \mathrm{E}-18$ & cg06022942 & 10 & 8095484 & FLJ45983 & TSS200 & $2.5882 \mathrm{E}-19$ \\
\hline 11 & $7.95 E-24$ & $3.53 \mathrm{E}-14$ & $3.86 \mathrm{E}-12$ & ch.6.1693624F & 6 & 83767401 & UBE2CBP & Body & $3.4576 \mathrm{E}-19$ \\
\hline 12 & $1.32 \mathrm{E}-23$ & $5.62 \mathrm{E}-09$ & $4.06 \mathrm{E}-17$ & cg24954207 & 3 & 128217091 & & & $5.2626 \mathrm{E}-19$ \\
\hline 13 & 1.77E-23 & 4.00E-09 & $7.68 \mathrm{E}-17$ & cg08234504 & 5 & 139013317 & & & $6.5138 \mathrm{E}-19$ \\
\hline 14 & $1.92 \mathrm{E}-23$ & $8.17 \mathrm{E}-11$ & $4.10 E-15$ & cg02492920 & 7 & 150659969 & $\mathrm{KCNH} 2$ & Body & $6.5384 \mathrm{E}-19$ \\
\hline 15 & $2.05 E-23$ & $1.01 \mathrm{E}-11$ & $3.53 \mathrm{E}-14$ & cg14299508 & 8 & 105907690 & & & $6.5384 \mathrm{E}-19$ \\
\hline 16 & $3.75 E-23$ & $2.50 E-12$ & $2.64 \mathrm{E}-13$ & cg08594681 & 8 & 27468684 & $\mathrm{CLU}$ & 1stExon & $1.1213 \mathrm{E}-18$ \\
\hline 17 & $4.63 E-23$ & $6.45 E-14$ & $1.27 \mathrm{E}-11$ & cg08342886 & 6 & 33240066 & VPS52 & TSS1500 & $1.303 \mathrm{E}-18$ \\
\hline 18 & $1.20 E-22$ & $9.22 \mathrm{E}-10$ & $2.34 \mathrm{E}-15$ & cg00303378 & 1 & 159825552 & VSIG8 & Body & $3.0971 \mathrm{E}-18$ \\
\hline 19 & $1.23 \mathrm{E}-22$ & $1.21 \mathrm{E}-10$ & $1.83 \mathrm{E}-14$ & cg23813012 & 1 & 14026482 & PRDM2 & TSS1500 & $3.0971 \mathrm{E}-18$ \\
\hline 20 & $1.38 \mathrm{E}-22$ & $5.01 \mathrm{E}-10$ & $4.98 \mathrm{E}-15$ & ch.13.22912778R & 13 & 24014778 & & & $3.2806 \mathrm{E}-18$ \\
\hline 21 & $1.44 \mathrm{E}-22$ & $1.20 \mathrm{E}-08$ & $2.17 \mathrm{E}-16$ & cg06639320 & 2 & 106015739 & FHL2 & TSS200 & $3.2806 \mathrm{E}-18$ \\
\hline 22 & 1.77E-22 & $1.31 \mathrm{E}-09$ & $2.45 E-15$ & cg15393490 & 1 & 207996459 & & & $3.8491 \mathrm{E}-18$ \\
\hline 23 & $1.90 \mathrm{E}-22$ & $6.33 \mathrm{E}-08$ & $5.46 \mathrm{E}-17$ & cg26880525 & 1 & 209877941 & HSD11B1 & 5UTR & $3.8672 \mathrm{E}-18$ \\
\hline 24 & $1.94 \mathrm{E}-22$ & $6.83 \mathrm{E}-13$ & $5.17 \mathrm{E}-12$ & cg04211309 & 16 & 58056296 & & & $3.8672 \mathrm{E}-18$ \\
\hline 25 & $2.33 \mathrm{E}-22$ & $5.12 E-15$ & $8.29 E-10$ & cg09131339 & 1 & 109914235 & SORT1 & Body & $4.4588 \mathrm{E}-18$ \\
\hline
\end{tabular}

detected many aging-DMCGs with large methylation differences between young and old individuals (Fig. 2a, c; Additional file 1: Fig. S2a) there was only a minor overlap $(n=49)$ of the top 1000 aging-DMCGs between neurons and glia (Fig. 2b), indicating distinct methylation dynamics for both cell-types upon aging (Additional file 2: Tables S12, S13). Most aging-DMCGs were found in gene body, promoter and first exon regions while intergenic regions were underrepresented (Fig. 2d, e). For both cell-types, we predominantly observe a hypomethylation with increasing age (Fig. 2d, Additional file 1: Fig. S3). For several genes in the top 1000 lists, we observed prominent age-associated changes in neurons such as FAM53B (10 hits), CLU (8) and NCOR2 (6) (Additional file 2: Table S14). All the three genes encode proteins important for neuronal processes [36, 54, 60]. Interestingly, the aging-DMCGs at the $C L U$ gene are specifically concentrated in the first intron (Fig. 2f) at a previously described alternative promoter where a specific CLU isoform is initiated from $[11,74]$. These CpGs show a strong loss of DNA methylation with increasing age in neurons
(Additional file 1: Fig. S4). The effect is independent of $\mathrm{AD}$ as we observe this in healthy controls and $\mathrm{AD}$ samples to the same extent. In nuclei from glia, we confirmed aging-DMCGs at loci which were previously described as aging markers in peripheral blood such as ELOVL2 and FHL2 [59]. In addition, we identified a set of new genes with clustered and prominent aging-DMCGs glia such as RAI1 (6 hits), CUX1, DIP2C, FLJ45983 and ITPK1 (all 5) (Additional file 2: Table S14). For both neurons and glia, the top ten aging-associated KEGG pathways featured ErbB signaling pathway, Neuroactive ligand-receptor interaction and MAPK signaling pathway (Additional file 2: Table S19). Notably, we found numerous agingDMCGs with asymmetric or even opposing methylation dynamics in neurons and glia, respectively (Fig. 2g, Additional file 1: Fig. S5). Such cases nicely illustrate the complexity of aging across cell-types and the advantage of cell sorting over bulk tissue.

Among genes with multiple age-dynamic ct-DMCGs (Additional file 2: Table S15) we identify prominent candidates with negative cell-type-specific aging dynamics 
(i.e., neuron-glia differences are decreased in old individuals compared to young ones) such as C21orf34 (6 hits), ANK1 (5), PTPRN2 (5), HDAC4 (5), but also APP (2).

$A N K 1$ was recently reported as a top differentially methylated marker associated with Braak stage progression in two large EWAS [27, 82]. Indeed we find that the two top ANK1 CpGs and several others reported in these studies exhibit strong and complex cell-type dynamics overage (Additional file 1: Fig. S6). Increased cell-type-specific aging dynamics were also seen in DIP2C5 (5) and PAX6 (5). The latter encodes an transcription factor that is important in the development processes of neural tissues and has been implicated in healthy aging and AD [81].

Next, we independently validated our top agingDMCGs using another public cohort of NeuN-sorted prefrontal cortex brain samples [61]. From this dataset (GSE98203), we only used healthy, NeuN-positive controls as NeuN-negative data was not available. For our top 50 neuronal aging-DMCGs we found highly similar methylation dynamics overage in these samples (examples see Additional file 1: Fig. S7) illustrating that our approach is valid. These findings may have profound implications for the interpretation of epigenetic effects in age-related diseases. In many studies, bioinformatic methods are used to adjust tissue samples for cell composition effects $[46-48,104]$ which is inferred from reference datasets. In the light of our observations, this procedure could be problematic if the used references and tissue samples have a different age distribution because the tool potentially selects discriminative markers that have diverse aging dynamics. Indeed, our in silico estimations of neuronal content in brain tissue show systematic differences depending on the usage of a reference set of young age or of old age (Additional file 1: Fig. S8a, b). In addition to that we find high variation of neuronal content across all studies and tissues analyzed (Additional file 1: Fig. S8c). Our analysis emphasizes that cell-type-specific methylation dynamics upon aging are prominent and have to be considered as complex confounding factors in epigenetic studies of brain tissues.

\section{Both neurons and glia show Braak stage-associated methylation changes}

We then focused on the association of DNA methylation with Braak stage progression in neurons and glia cells, respectively (Fig. 3a, b, Table 2). Similar to the previous analysis we analyzed neuron and glia separately and applied regression models that used the samples' individual Braak score as a factor. In addition, we corrected for potential confounding variables (aging, sex and batch effects). Again, we observe reduced overlap between the top 1000 Braak-DMCGs of both cell-types
(Fig. 3c) indicating that neuronal and glia cells respond differentially during $\mathrm{AD}$ progression. For numerous Braak-DMCGs we could observe unbalanced or even reciprocal methylation dynamics in neurons and glia upon Braak stage progression (Additional file 1: Fig. S9). These diametric methylation changes in the two major cell-types of the brain could not be detected in bulk brain tissue screens but rather be interpret as changes in cell proportions. Similarly, the overlap between top BraakDMCGs and aging-DMCGs is small (Fig. 3d, e), suggesting differential methylation dynamics for aging and Braak stages. Approx. $60 \%$ of DMCGs become hypomethylated with increasing Braak stages (Additional file 1: Fig. S10). They are mostly located in gene body, promoters and first exon regions (Fig. 3f) while intergenic regions were largely underrepresented (Fig. 3g). Absolute methylation differences for the top 1000 Braak-DMCGs remained small but clearly higher than the overall changes seen in tissue-based analyses (Fig. 3h, Additional file 1: Fig. S1j). The top ranked neuronal Braak-DMCGS are located at genes involved in cortical neurotransmitter transport. For example, the top-ranking CpG, "cg02746913" ( $p$ value : $1.23 * 10^{-07}$; Additional file 2: Table S16) is located proximal to the gene SEC14L1 [108]. The top 3 ranking site, "cg06549928" ( $p$ value : $1.15 * 10^{-06}$, Fig. 4c, Additional file 2: Table S16) is located at the LRRC8B locus [87]. In addition, we identify clusters of DMCGs in genes such as MCF2L (7 hits), FAM83H (6), ARSG (3) and $H O X A 3$ (3) (Additional file 2: Table S14).

The glial top marker "cg06549928" ( $p$ value : $3.83 * 10^{-9}$; Additional file 2: Table S17) in the gene $L R R C 8 B$ was also found to be prominent in our neuron analysis. Clustered glia DMCGs were associated with DIP2C (6 hits), HLA-DPB1 (6), GNG7 (5) and HOPX (5) (Additional file 2: Table S14). GNG7 encodes for a calcium-dependent $\mathrm{G}$ coupled receptor that is coupled to dopamine receptors and its expression level in astrocytes becomes upregulated upon inflammatory stimuli $[24,37$, $112,114]$. In our list of top glial DMCGs we further identify two hits in the ANK1 gene (Additional file 2: Tables S14, S17) recently reported as the top marker in two large AD screens on bulk tissue [27, 82]. Our data suggest that the reported epigenetic changes in $A N K 1$ are restricted to glia.

\section{Meta-analysis for Braak stage progression detects robust methylation changes in HOXA3, APP and ANK1}

Next, we reasoned that a combination of the cell-typespecific results from the neuron and glia analyses should reflect the combined epigenetic burden in the CNS upon Braak stage progression. The combined meta-analysis was performed using Fisher's Method and results were ranked according to $p$ values (Fig. 4a, Table 2). As 
Table 2 Top 10 Braak stage DMCGs plus 25 selected CpGs from 200 top entries

\begin{tabular}{|c|c|c|c|c|c|c|c|c|c|c|}
\hline Rank & $\begin{array}{l}P \text { value } \\
\text { (meta- } \\
\text { analysis) }\end{array}$ & $P$ value (neuron) & $P$ value (glia) & TargetID & Chr & Position & Gene & Region & Probe SNPs & FDR \\
\hline 1 & $1.50 \mathrm{E}-13$ & $1.15 E-06$ & $3.83 \mathrm{E}-09$ & cg06549928 & 1 & 89990868 & LRRC8B & 5UTR & & 7.17624E-08 \\
\hline 2 & $6.43 \mathrm{E}-11$ & $4.64 \mathrm{E}-06$ & $4.98 \mathrm{E}-07$ & cg21913630 & 7 & 128828599 & $\mathrm{SMO}$ & TSS200 & & $1.53811 \mathrm{E}-05$ \\
\hline 3 & $2.05 E-10$ & $3.04 \mathrm{E}-05$ & $2.54 \mathrm{E}-07$ & $\operatorname{cg} 16562251$ & 1 & 166845621 & TADA1 & 1stExon & & $3.26918 \mathrm{E}-05$ \\
\hline 4 & $2.90 \mathrm{E}-10$ & $1.15 E-05$ & $9.63 \mathrm{E}-07$ & cg08738571 & 12 & 32655192 & FGD4 & 1stExon & rs56168193 & $3.45416 \mathrm{E}-05$ \\
\hline 5 & $3.61 \mathrm{E}-10$ & $9.00 \mathrm{E}-06$ & $1.54 \mathrm{E}-06$ & cg22140756 & 2 & 177895827 & & & & $3.45416 \mathrm{E}-05$ \\
\hline 6 & $4.81 \mathrm{E}-10$ & $7.42 \mathrm{E}-06$ & $2.52 \mathrm{E}-06$ & cg04913265 & 11 & 133939627 & JAM3 & Body & & $3.8353 \mathrm{E}-05$ \\
\hline 7 & $8.78 \mathrm{E}-10$ & $1.69 \mathrm{E}-05$ & 2.07E-06 & cg20693608 & 4 & 113152836 & AP1AR & TSS200 & & $6.0007 E-05$ \\
\hline 8 & 1.57E-09 & $7.82 \mathrm{E}-06$ & $8.20 E-06$ & cg24449302 & 15 & 66679100 & MAP2K1 & TSS200 & rs77540803 & 7.02674E-05 \\
\hline 9 & 1.60E-09 & $7.69 E-06$ & $8.51 \mathrm{E}-06$ & $\operatorname{cg} 13172549$ & 7 & 27153636 & HOXA3 & 5UTR & & 7.02674E-05 \\
\hline 10 & $1.61 \mathrm{E}-09$ & $2.63 \mathrm{E}-06$ & $2.50 E-05$ & cg04547723 & 14 & 75421960 & PGF & 5UTR & & 7.02674E-05 \\
\hline 11 & 1.67E-09 & $1.49 \mathrm{E}-05$ & $4.58 \mathrm{E}-06$ & cg07835289 & 1 & 236030215 & LYST & 5UTR & & 7.02674E-05 \\
\hline 15 & 2.27E-09 & 0.00021772 & 4.33E-07 & cg11817993 & 14 & 92572978 & ATXN3 & TSS200 & & 7.02674E-05 \\
\hline 21 & $5.19 \mathrm{E}-09$ & $3.14 \mathrm{E}-05$ & $7.12 \mathrm{E}-06$ & cg02037503 & 14 & 23540729 & ACIN1 & 1stExon & & 0.000118237 \\
\hline 27 & $1.04 \mathrm{E}-08$ & 7.43E-05 & $6.24 \mathrm{E}-06$ & cg03040740 & 13 & 99084682 & FARP1 & Body & rs6491426 & 0.000184279 \\
\hline 32 & 1.44E-08 & 0.00087784 & $7.40 \mathrm{E}-07$ & cg13859639 & 11 & 2846716 & KCNQ1 & Body & & 0.000215287 \\
\hline 38 & $2.41 \mathrm{E}-08$ & 0.00041341 & $2.70 E-06$ & cg03907612 & 6 & 41703314 & TFEB & 5UTR & & 0.000303416 \\
\hline 39 & $2.60 E-08$ & $7.11 \mathrm{E}-05$ & 1.70E-05 & cg16568373 & 17 & 4853368 & ENO3 & TSS1500 & & 0.000318944 \\
\hline 48 & $3.48 \mathrm{E}-08$ & $2.84 \mathrm{E}-05$ & $5.76 \mathrm{E}-05$ & cg05884192 & 14 & 52515736 & NID2 & Body & rs2516585 & 0.000334891 \\
\hline 53 & $3.75 E-08$ & 0.00012506 & $1.42 \mathrm{E}-05$ & cg08883485 & 1 & 201619787 & NAV1 & Body & & 0.000334891 \\
\hline 58 & $4.55 \mathrm{E}-08$ & $4.14 \mathrm{E}-05$ & $5.24 \mathrm{E}-05$ & cg23712970 & 14 & 23540735 & ACIN1 & 1stExon & & 0.000374624 \\
\hline 74 & $6.71 \mathrm{E}-08$ & $1.05 E-05$ & 0.0003106 & cg08843538 & 2 & 210288784 & MAP2 & 1stExon & & 0.000429299 \\
\hline 76 & $6.94 \mathrm{E}-08$ & $4.79 E-05$ & 7.07E-05 & cg04542489 & 14 & 23775746 & BCL2L2 & TSS1500 & & 0.00043306 \\
\hline 102 & $1.24 \mathrm{E}-07$ & $4.82 E-05$ & 0.00012891 & cg06355720 & 1 & 153333350 & S100A9 & 3UTR & rs743566 & 0.000581604 \\
\hline 103 & 1.27E-07 & 5.37E-05 & 0.00011905 & cg26327118 & 6 & 39693366 & KIF6 & TSS200 & & 0.000589892 \\
\hline 104 & $1.31 \mathrm{E}-07$ & $1.08 \mathrm{E}-05$ & 0.00061189 & cg16258854 & 2 & 20648194 & $\mathrm{RHOB}$ & 1stExon & rs1062292 & 0.000595763 \\
\hline 111 & $1.41 \mathrm{E}-07$ & 0.00052315 & 1.36E-05 & cg08866780 & 21 & 27543523 & APP & TSS1500 & & 0.000604315 \\
\hline 112 & $1.42 \mathrm{E}-07$ & 0.01466411 & $4.90 \mathrm{E}-07$ & cg03613822 & 17 & 7115140 & DLG4 & Body & & 0.000604315 \\
\hline 126 & $1.71 \mathrm{E}-07$ & $5.41 \mathrm{E}-06$ & 0.00161641 & cg06291595 & 14 & 74960292 & NPC2 & TSS1500 & & 0.000646609 \\
\hline 131 & $1.86 \mathrm{E}-07$ & 0.01071281 & $8.90 \mathrm{E}-07$ & cg04153489 & 8 & 41655983 & ANK1 & TSS1500 & & 0.000679278 \\
\hline 133 & 1.99E-07 & 2.07E-05 & 0.00049571 & cg19447671 & 2 & 176032513 & ATF2 & 5UTR & & 0.000715825 \\
\hline 134 & $2.04 \mathrm{E}-07$ & 0.00058734 & 1.79E-05 & cg10313337 & 16 & 68823690 & $\mathrm{CDH} 1$ & Body & & 0.000728335 \\
\hline 141 & $2.18 \mathrm{E}-07$ & 0.00020684 & 5.47E-05 & cg01015899 & 12 & 120663812 & PXN & 5UTR & & 0.000737839 \\
\hline 152 & $2.41 \mathrm{E}-07$ & $2.45 E-05$ & 0.00051347 & cg27212541 & 3 & 49507385 & DAG1 & TSS200 & & 0.00075801 \\
\hline 161 & $2.68 \mathrm{E}-07$ & 0.00027187 & $5.17 \mathrm{E}-05$ & cg07745886 & 8 & 42150794 & IKBKB & Body & & 0.000796369 \\
\hline 199 & $4.19 \mathrm{E}-07$ & 0.00095868 & $2.35 \mathrm{E}-05$ & cg01231165 & 2 & 9695142 & ADAM17 & Body & & 0.001001966 \\
\hline
\end{tabular}

\section{(See figure on next page.)}

Fig. 2 Aging analysis in neurons and glia. a Genomic $p$ value distribution for the aging analysis in neurons. The arrow marks a region on chromosome 8 with a concentrated set of top-ranking CpGs (see f). b Overlap of top 1000 aging-DMCGs between neuron and glia, but approx. 25\% of each set are ct-DMCGs. c Methylation change from 8 youngest to 8 oldest samples for top 1000 aging CpGs in neurons and glia, respectively. Boxes colored as in $\mathbf{d}$. $\mathbf{d}$ Genomic region classification of top 1000 aging-DMCGs from neuron and glia, respectively. CpGs are classified in respect of hypo- or hypermethylation in 8 oldest versus 8 youngest CTRL samples. e Relative distribution of top 1000 aging-DMCGs in relation to array design. f $p$-value distribution at the clusterin gene locus $(C L U)$ in the age analysis in neuron (green) and glia (red), respectively. A set of 10 adjacent CpGs (dashed square) shows strong age-association in healthy neurons (but only partially in glia). Numbers on $x$-axis give coordinates on chromosome 8 (hg19). Cartoon below illustrates the relative location of exons (black boxes), promoters (black triangles) and annotated sites of high DNasel hypersensitivity (gray boxes) according to UCSC genome browser. g Age-dependent methylation changes that occur exclusively in one cell-type can lead to either emergence (left panel) or disappearance (mid) of significant differences between cell-types. Aging effects that are synchronized between cell-types are stable ct-DMCGs over lifetime (right). Adding AD samples leads to similar results (bright dashed lines: regression lines based on CTRLs, dark dashed lines: CTRLS + AD cases) (color figure online) 


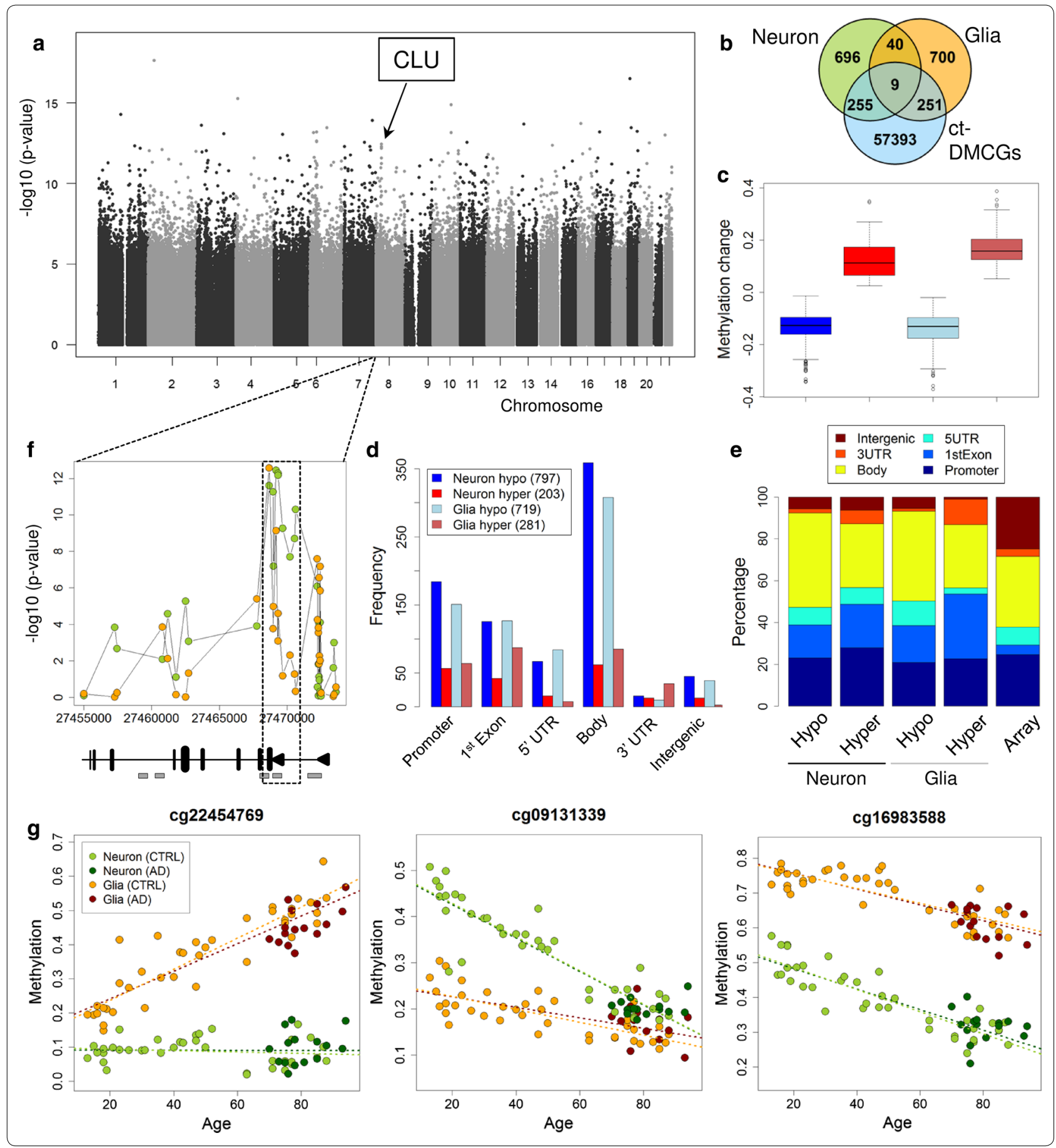

a plausibility check for our approach, we performed a cluster analysis of the 200 top-ranking combined BraakDMCGs using all samples. The clustering shows an almost perfect cell-type-specific split on the first level but on the second or third split disease-related subclusters (Fig. 4b). In our top 200 list (Additional file 2: Tables S14, S18) the most covered KEGG pathways were 'MAPK signaling, 'neurotrophin signaling' and 'Alzheimer's disease' (Additional file 2: Table S19). We identified multiple hits for the HOXA3 gene with a high significance for four CpGs ('cg13172549', 'cg07061298', 'cg00921266', 'cg22962123'; ranks: 10, 44, 91 and 158). All four CpGs show a solid hypermethylation upon Braak stage progression with more pronounced changes 

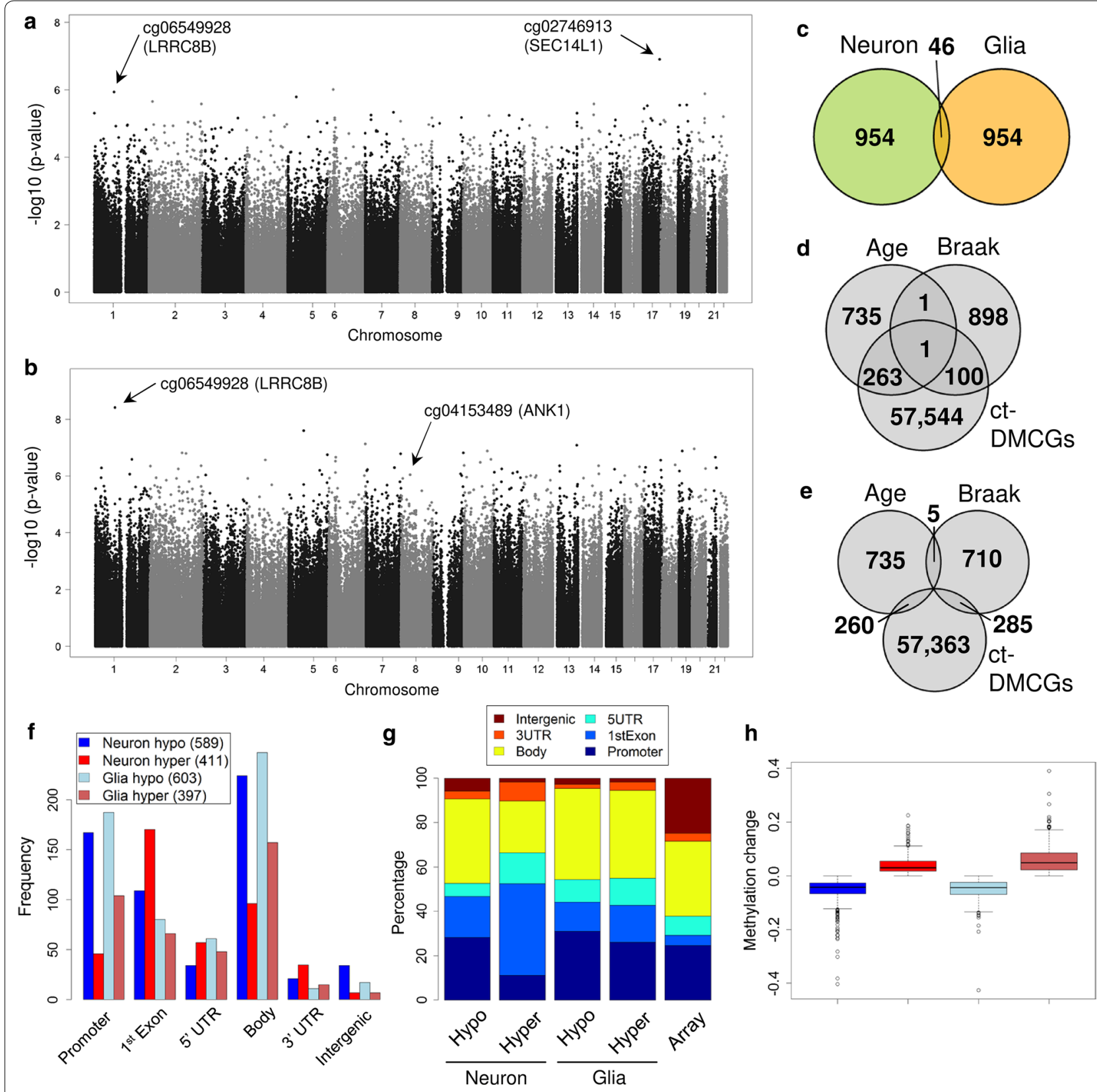

Fig. 3 Braak stage analysis in neuron and glia. a Genomic $p$ value distribution for the Braak stage progression analysis in neurons. b Genomic $p$ value distribution for the Braak stage progression analysis in glia. c Overlap for the top 1000 ranking Braak-DMCGs from neuron and glia. d Overlap of top 1000 Braak-DMCGs and top 1000 aging-DMCGs from neuron, 10\% of Braak-DMCGs are ct-DMCGs. e Same as $\mathbf{d}$ but for glia top DMCGs. Compared to neuron there are more ct-DMCGs among top Braak-DMCGs in glia. $\mathbf{f}$ Distribution across genomic regions of top 1000 Braak-DMCGs from neuron and glia. CpGs were classified as hypo- or hypermethylated in respect to methylation change from 8 youngest CTRLs to 8 oldest Braak stage VI samples. Most methylation changes are at gene body, promoters and 1st exon regions. $\mathbf{g}$ Similar to $\mathbf{f}$ but in relation to array design. $\mathbf{h}$ Methylation changes from 8 youngest CTRLs to 8 oldest Braak stage VI samples for top 1000 Braak-DMCGs in neurons and glia, respectively. Boxes colored as in $\mathbf{f}$ (color figure online)

in glia (Fig. 4c, Additional file 1: Fig. S5). Two of these four DMCGs HOXA3 were recently reported in a large EWAS screen by Lunnon et al $[27,82]$ analyzing several hundred samples. To systematically examine the overlap between our top 200 markers with all published large tissue-based EWAS studies we retrieved the methylation data from publicly available tissue-based AD datasets (GSE59685, GSE80970). Together with our own 
(See figure on next page.)

Fig. 4 Meta-analysis and integration of external brain tissue data. a Manhattan plot for the Braak stage meta-analysis. Selected CpGs located at the genes $\angle R R C 8 B, H O X A 3$ and APP are marked by arrows. b Cluster analysis for the 200 top-ranking Braak-DMCGs. c Methylation change over Braak stages for exemplary top CpGs at the genes HOX3A (top), LRRC8B (middle) and APP (bottom). Box colored as in $\mathbf{b}$. $\mathbf{d}$ Methylation change between Braak stages for various CpG sets based on our own data (Study 1: our sorted and tissue samples) or on external tissue data (Study 2: GSE59685 [82]; Study 3: GSE80970 [121]). Rows are organized as sets of CpGs derived from our own 200 top-ranking results (neuron, glia, meta-analysis), the top 100's from Lunnon and partners (FC, TC, EC, CER) and 100 randomly selected sites. Dashed squares indicate the dataset initially used to identify the corresponding CpG set. 'Cross study' depicts two CpGs at the HOXA3 locus co-identified in our screen and in Study 2. Note that for most CpGs the methylation difference across Braak stages are strongest in sorted samples even when the CpG set was originally identified in tissues. (FC: frontal cortex, TC: temporal cortex, EC: entorhinal cortex) (color figure online)

dataset this meta-analysis comprised about 700 samples from three brain regions (frontal, temporal, occipital and entorhinal cortex). Following a uniform data processing, we calculated absolute methylation changes between low, middle and high Braak stages for the individual top CpGs (Fig. 4d). We compared the changes associated with Braak progression for our top Braak-DMCGs (top 200 neuron, top 200 glia, top 200 combined analysis) and the top 100 lists from tissue-based EWAS (Fig. 4d). This confirmed two of the four $H O X A 3$ gene markers across all studies and a remarkable overlap for many more previously reported DMCGs (Fig. 4d, Additional file 1: Fig. S8). For the majority of these DMCGs methylation changes were more pronounced in sorted cells than in bulk samples (Additional file 1: Fig. S12) and interestingly often found in glial cells (e.g., ANK1). Notably, among the novel Braak-DMCGs in our top 200 DMCGs we found a marker near the APP gene (cg08866780, $p=1.41 * 10^{-7}$, rank 111, Fig. 4c, Additional file 2: Table S18) one of the most relevant $\mathrm{AD}$ genes $[39,115]$. The DMCG is located in the APP promoter and becomes hypomethylated during Braak stage progression in neurons and in glia but starting from different basal levels (Fig. 3c). This CpG did not show significant changes upon aging in controls only (neuron: $P=0.4$, glia: $p=0.46$ ) and the effect remained when only individuals older than 64 years were considered (Additional file 1: Fig. S11a) suggesting an ageindependent methylation change at the APP promoter linked to Braak stage. Methylation changes for $A P P$ were not detected in our bulk brain tissue samples (Additional file 1: Fig. S11b) nor reported in the top 100 lists from tissue screens $[27,82]$ indicating a gain of sensitivity for pre-sorted samples.

\section{Discussion}

Our first systematic cell-type-specific DNA methylation screen on a cohort of postmortem cortex samples shows that cell sorting strongly enhances the detection of DNA methylation markers and allows a deep insight into cell-type-specific dynamics in the context of aging and $\mathrm{AD}$ Braak stage progression, respectively. In general, we observe a deep interplay between DNA methylation changes associated with aging, with cell-type and with disease progression. Many CpGs reveal distinct methylation dynamics during aging in neurons and glia, respectively. This suggests that the biological "clock" of neuronal and glial cells show characteristic epigenetic signatures in the brain. Nevertheless, we also found CpGs with 'synchronized' dynamics across the two cell-types (such as in the pan-aging marker ELOVL2). In the context of a highly age-related and complex disease such as $\mathrm{AD}$, it is of great value to better understand epigenetic effects linked to aging as it supports the interpretation of molecular changes. Starting off with a conventional tissue-based screen of unsorted cortical tissues from a representative cohort of 128 well diagnosed healthy donors and $\mathrm{AD}$ patients we realized that this approach comes with a low detection power and consequently a minimal number of epigenetic markers which moreover mostly do not overlap with other large EWAS studies. To overcome this obstacle we developed a sorting protocol for neuronal and glial nuclei fractions and performed two simultaneous $450 \mathrm{~K}$ analyses per donor. In line with recently published data [35], we find tens of thousands robust methylation changes between the neuronal and glial fractions. This strong overlap and the high similarity of samples (age- and sex-matched) between the two studies illustrate the high reproducibility of the cell sorting approach. By using linear regression models we then identified robust cell-type-specific DNA methylation differences associated with either aging or Braak stage progression (or both). While age-associated changes have been reported previously on mixed tissues $[58,118]$ our study highlights the presence of cell-specific age-related methylation dynamics in human primary cells such as neuron and glia. This finding is well compatible with findings reported by others [122] who found age-specific transcriptional differences between neuron and glial cells in the human brain. As one prominent example, we identify a cell-type-specific cluster of age-associated DMCGs located in an alternative promoter of the clusterin $C L U$, a well-known AD risk gene $[8,30,40,67,69,94,94,110$, 138, 141, 143, 145]. At this promoter, neurons become increasingly hypomethylated over lifetime-while 


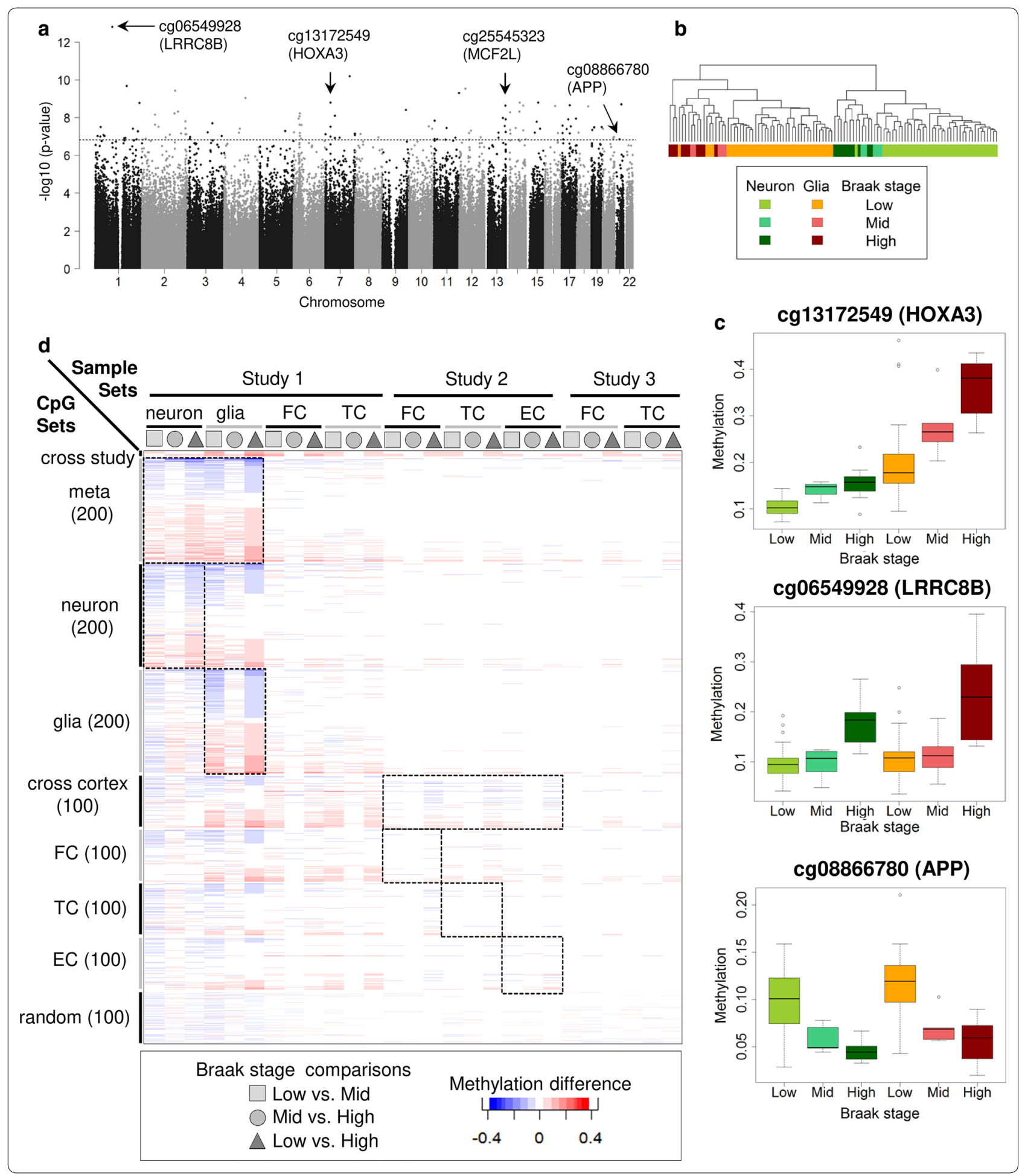

changes in glia are only moderate or absent. This effect is independent of $\mathrm{AD}$ diagnosis indicating that the epigenetic changes in CLU are a sign of "natural aging" contributing to disease aetiology. In the human two distinct
CLU isoforms have recently been described with opposing functions in cell survival and apoptosis [21, 28, 73, $130,131]$. Our data indicate that an alternative promoter becomes epigenetically "activated" in aged neurons and 
the expression of a pro-apoptotic CLU isoform may contribute to degeneration predominantly in the CNS. Our observation that over lifetime cell-type-specific DMCGs can emerge or vanish indicates that besides cell composition age represents a complex confounding parameter in tissues based EWAS. Our studies show that such phenomena require strong attention particularly when using cell-type-specific data as references for calculation of cell-type proportions and adjustments. We believe that our analysis combined with data from Guintivano et al. represents a valid resource to appropriately identify and interpret age-related effects for data deconvolution. Moreover, we were able to replicate our top neuronal aging-DMCGs in an independent dataset which nicely illustrates that our findings are reproducible. The main goal of our study was to identify DMCGs associated with Braak stage progression on a cell-type-specific basis. In line with earlier studies, we detected DMCGs in several genes involved in neurotransmitter homeostasis and transport such as SEC14L1, MCF2L and LRRC8B [41, 87, 108]. In $A D$, neurotransmitter systems are largely disturbed [32, 90] and it is known that ACh-releasing neurons are explicitly vulnerable to amyloid beta 1-42 exposition and predominantly lost upon Braak stage progression $[4,99,113]$. In line with this interpretation, we find epigenetic changes in three genes. $M C F 2 L$ encodes a protein involved in the Mcf2l-RhoA-ROCK signaling pathway that mediates Il1rapl1-dependent formation and stabilization of glutamatergic synapses of cortical neurons [41]. SEC14L1 encodes a protein involved in vesicular trafficking of acetylcholine (ACh) to synaptic vesicles [108]. The LRRC8 genes encode for anion channels that transport the neurotransmitters glutamate, aspartate and gamma-aminobutyric acid (GABA) and the LRRC8B protein has been reported to modulate the substrate specificity of the channels [87]. Most intriguingly the very prominent changes for $L R R C 8 B$ in both neuronal and glial cells indicate that this anion channel gene plays a multiple role in the $\mathrm{AD}$ pathology. Among the many DMCGs changing in glial cells upon Braak stage progression, we found two prominent CpGs in the ANK1 gene, a gene recently reported as a top candidate in two large EWAS based on hundreds of bulk tissue samples [27, 82]. Our finding underlines that these top markers predominantly change in glia cells. Indeed, a recent study using laser microdissection reported increased ANK1 expression in AD microglia but not in neurons or astrocytes [92]. To evaluate the neuronal and glial "epigenetic burden" in the AD brain upon Braak stage progression we performed a meta-analysis combining the data of significant "clean", i.e., cell separated, DMCGs from glia and neuron. This combined analysis validates a series of concurrent changes in known AD genes such as $A P P, H O X A 3$ and $A D A M 17$ and confirms potentially new AD loci such as $L R R C 8 B$ and MCF2L. The detection of a Braak stage-associated epigenetic change in the APP gene is of particular importance. To our knowledge, we report the first systematic analysis confirming a few unlinked single case reports $[52,129,137]$ for $A P P$. This DMCG is located at the promoter overlapping with a confirmed CTCF binding region (Additional file 1: Fig. S11c). This region has been shown to regulate APP transcription [133, 134, 142]. Our data suggest that during $\mathrm{AD}$ progressive loss of DNA methylation at this region results in enhanced binding of CTCF thus increasing APP transcription. Our analysis further identifies six CpGs high ranking Braak-DMCGs at the HOXA3 gene. Several of them were previously reported by recent large EWAS studies [27, 82, 121]. With the help of cell sorting, we could detect these signals in a much smaller cohort illustrating the gain of sensitivity after separation of major cell-types. The HoxA gene cluster is known to coordinate neuronal development, organization of neural circuits and regulation of postmitotic neurons [79, 91, 101,135] and abnormal expression or epigenetic dysregulation of Hox genes has been reported for several neurological diseases such as Huntington's disease, Parkinson's disease, C9ORF72-related dementias and glioblastoma [31, 45, 65, 66, 78, 139].

There are several limitations to our work. We used classic bisulfite conversion chemistry in our study that is known to be masked for 5-mC and 5-hmC. Future work could employ methods, such as oxidative or Tet-assisted bisulfite conversion to elaborate alterations of individual methylation forms. Further, for AD an predominant loss of pyramidal neurons has been reported [12]. Therefore, some of our results might reflect a shift in neuronal subtype proportions. Additional sorting of neuronal and glial fractions into subpopulations such as dopaminergic, glutamatergic and GABAergic neurons or glial subtypes (astrocytes, oligodendrocytes and microglia) could further enhance the sensitivity of such screens like ours. Indeed combined FACS separation with NeuN and SOX6 has been shown to effectively separate glutamatergic and GABAergic neurons in mouse and identified clear additional neuronal epigenetic differences [62]. However, to date, only these two markers are available and have not been successfully used for postmortem human tissues probes. An alternative approach to dissect the nature of heterogeneity by single nuclei analyses. Such promising approaches have recently been applied on single NeuNpositive nuclei in mouse and human [84], but are still not in a robust state for large-scale comparative studies on challenging postmortem material. Moreover, we included combined nuclei sorted from occipital cortex and frontal cortex in our study to increase sample size. 
While in brain tissue-based screens strong methylation differences across brain regions have been shown [26, 43], this was so far not observed in sorted NeuN-negative (glia) nuclei [109]. For NeuN-positive samples limited methylation changes were found only between certain regions [109]. Further studies are required to systematically dissect neuronal methylation differences across and within specific brain regions, especially in the cortex. However, in our Braak association analysis, we do not see an enrichment of cell-type markers exclusively found in frontal cortex or in occipital cortex (Additional file 2: Table S21).

\section{Conclusions}

We demonstrate the application of our approach requires a relatively small cohort to robustly identify new and assign known disease-associated epigenetic signals to specific cell populations. We conclude that sorting for major cell-types enables systematic EWAS with less samples compared to common tissue-based screens reducing time, costs and labor. Taken together, our study highlights cell-type composition and aging as major confounding factors in complex tissue analyses and strongly recommends to conduct EWAS on pre-sorted cell-types.

\section{Methods}

\section{Human brain tissue samples and neuropathological} classification of AD

For our study, we used snap-frozen human postmortem cortical tissue from 159 individuals that donated their brains for research (Additional file 2: Tables S1, S2). For 128 frontal and temporal cortex samples, we used the bulk tissue while for the 31 occipital cortex samples (Brodmann Area 17-19) we isolated neuronal and glial nuclei populations. Samples were provided by the Neurobiobank Munich (NBM) and are well characterized by age, gender, disease history and neuropathological findings including Braak stage measurements in the analyzed subregions. All cases were collected according to the NBM standard protocols established by the BrainNet Europe and BrainNet Germany. Written informed consent was obtained according to the guidelines of the local ethics committee. Besides samples stored at $-80^{\circ} \mathrm{C}$ for molecular analysis some parts of the brains were formalin-fixed and paraffin-embedded (FFPE) for detailed anatomical and neuropathological evaluations: According to the NBM standards, up to 25 different brain regions were analyzed and neuropathological reports were drawn in accordance with the National Institute on Aging-Alzheimer's Association guidelines for the neuropathologic assessment of Alzheimer's disease [50], the guidelines for the staging of Alzheimer disease-associated neurofibrillary pathology using paraffin sections and immunocytochemistry by Braak et al. [13], the CERAD (Consortium to Establish a Registry for Alzheimer's Disease) guidelines [95] and the phases of amyloid beta deposits in the human brain by Tahl et al. [126]. Donors with any indications for bleedings, infarctions, stroke, tumors or sepsis were not considered for this study.

\section{Separation of neuronal and glia nuclei}

Human postmortem occipital cortex (Brodmann area 17-19) neuronal and glia nuclei were separated by fluorescence-assisted isolation of immunolabeled nuclei using a NeuN- (RBFOX3-) specific antibody as described elsewhere [75, 93]. Thereby, most neuronal cell-types throughout the nervous system show positivity for NeuN, only distinct neuronal cell-types such as cerebellar Purkinje cells, olfactory bulb mitral cells and retinal photoreceptor cells stain negative [128]. Briefly, $600 \mathrm{mg}$ of cortex tissue was accurately dissected, cut into small pieces after removing of leptomeninx and dissolved in 11 $\mathrm{ml}$ tissue lysis buffer (TLB) (10 mM Tris- $\mathrm{HCl}$ (pH 8), 0.1 mM EDTA, $3 \mathrm{mM} \mathrm{Mg(Ac)} 2,5 \mathrm{mM} \mathrm{CaCl}_{2}, 1$ tablet proteinase inhibitor cocktail, $0.1 \mathrm{mM}$ PMFS, $0.16 \mathrm{mM}$ DTT, $0.1 \%$ Igepal, $0.32 \mathrm{M}$ sucrose). After homogenization by douncing, samples were transferred into ultracentrifugation tubes. Carefully $20 \mathrm{ml}$ of nuclei separation buffer (NSB) (10 mM Tris- $\mathrm{HCl}$ (pH 8), $3 \mathrm{mM} \mathrm{Mg(Ac)})_{2}, 1$ tablet proteinase inhibitor cocktail, $0.1 \mathrm{mM}$ PMFS, $0.16 \mathrm{mM}$ DTT, 1.8 M sucrose) were pipetted onto the bottom of the tubes. Separation of nuclei was performed using a Hitachi Sorvall Discovery 90SE ultracentrifuge with a Sorvall TH-641 rotator (Sorvall, Breda, Netherlands) at $24,400 \mathrm{rpm}\left(1 \mathrm{~h}, 4{ }^{\circ} \mathrm{C}\right)$. Nuclei pellets were resuspended in $4 \mathrm{ml}$ ice-cold nuclei protection buffer (NPB) $(2.7 \mathrm{mM}$ $\mathrm{KCl}, 137 \mathrm{mM} \mathrm{NaCl}, 1.8 \mathrm{mM} \mathrm{KH}{ }_{2} \mathrm{PO} 4,10 \mathrm{mM} \mathrm{Na}_{2} \mathrm{HPO}_{4}$, 1 tablet proteinase inhibitor cocktail) and incubated on ice for $20 \mathrm{~min}$. Neuronal nuclei were labeled by incubation for $1 \mathrm{~h}$ at RT with $6 \mu \mathrm{l}$ mouse-anti-NeuN-antibody (1 $\mathrm{mg} / \mathrm{ml}$ ) (Millipore, Eschborn, Germany) followed by addition of $6 \mu \mathrm{l}$ fluorescence-labeled secondary antibody (Alexa Fluor 546 goat-anti-mouse $(2 \mathrm{mg} / \mathrm{ml})$, Invitrogen, Darmstadt, Germany), 3 l DAPI (4,6-Diamidin-2-phenylindol, Roth, Karlsruhe, Germany) and another incubation for $1 \mathrm{~h}$ in the dark. After centrifugation $(8000 \mathrm{rpm}$, $30 \mathrm{~s})$ pellets were resuspended in $3 \mathrm{ml}$ ice-cold PBS and used for flow-cytometrical separation of neuronal $(\mathrm{NeuN}+/ \mathrm{DAPI}+)$ and glial nuclei $(\mathrm{NeuN}-/ \mathrm{DAPI}+)$ on a FACSAria II device (BD Biosciences, Frankin Lakes, USA). Purity of nuclear fractions was $>98 \%$ as checked by re-FACS and high-throughput fluorescence microscopy (IN Cell Analyzer 2000, GE Healthcare, Chalfont St. Giles, UK). 


\section{Infinium 450k bead chip methylation profiling and data analysis}

DNA extraction was performed using the QIAamp DNA Micro Kit (Qiagen, Hilden, Germany) according to the manufacturer's protocol. DNA was dissolved in $90 \mu \mathrm{l}$ nuclease-free water and centrifuged at 14,000 rpm for 1 min. DNA was stored at $-80^{\circ} \mathrm{C}$ for further use. Bisulfite treatment was performed using $1 \mu \mathrm{g}$ of genomic DNA in the EZ DNA Gold Methylation Kit (Zymo, Irvine, USA) according to manufacturer's protocol, except that the final elution volume was $12 \mu \mathrm{l}$. To assess DNA methylation signatures of $485,512 \mathrm{CpGs}$, we used Infinium HumanMethylation450 BeadChips (Illumina, San Diego, USA) according to the manufacturer's protocol. Arrays were scanned on an Illumina HiScan device.

\section{Data analysis}

For methylation data processing and analysis we essentially followed recent guidelines on 450k data analysis [72]. Briefly, we performed quantile normalization and background subtraction using the $\mathrm{R}$ package minfi [1] and batch effect correction with Combat [57] from the sva package [71]. Methylation calls were generated as beta values, ranging from 0 to 1 , representing $0 \%$ and $100 \%$ methylation, respectively. We removed probes with a detection $p$ value $>0.01$ in any samples. All samples had a probe call rate $>99 \%$ and showed very high correlations $\left(R^{2}=0.99\right)$ within cell-types (Additional file 1 : Fig. S13). Data from the study of Guintivano et al. [35] were downloaded from NCBI GEO database (GSE41826; only the 23 healthy Caucasian controls were used) and processed the same way as our own data. Two additional external brain tissue datasets (GSE59685 and GSE80970) were downloaded and used for detailed comparisons. Data was downloaded as processed beta values (dasen normalized, no background subtraction) and corrected for batch effects with Combat. For the cell-type-specific analyses on aging or Braak stage progression, we merged our sorted dataset with data from Guintivano and colleagues to obtain a combined dataset of 478,416 CpGs and 108 sorted samples (78 controls and 30 AD samples). Then we run a principal component analysis (Additional file 1: Fig. S2) and correlated the principal components (PC) to known variables. PC1 showed best correlation with array batches $\left(p=2.86 * 10^{-13}\right)$, PC2 with celltype $\left(p=8.8 * 10^{-97}\right)$, PC3 with sex $\left(p=4.29 * 10^{-43}\right)$ and PC4 with age $\left(p=1.08 * 10^{-17}\right)$. We applied multiple linear regression models to find associations of DNA methylation and Braak stages with correction for confounding factors age and sex. We also corrected for technical batch effects in our model by including principal components 1 (PC1) from a principal component analysis as it shows high correlation to array batches :

$$
C p G=\beta_{0}+\beta_{1} \text { Braak }+\beta_{2} A g e+\beta_{3} \operatorname{Sex}+\beta_{4} P C 1
$$

Since epigenomes are highly cell-type-specific we run this model separately for neuronal and glia samples. Then we performed a meta-analysis to combine results from the primary analyses using Fisher's method with:

$$
p=\chi^{2}\left(-2 * \sum(\log (p \text { values }))\right)
$$

Power analyses are difficult for EWAS as numerous markers have shown high correlations [72] and established methods to correct for multiple testings are likely to be too stringent. Therefore, if not noted otherwise we worked with nominal $p$ values as done in other recent EWAS [27, 82]. Nevertheless, we additionally provide FDR adjusted $p$ values in all relevant result tables. GO enrichment analyses were performed with the GOrilla tool using gene symbols according to Illumina annotation. KEGG pathway analyses were performed by converting relevant $\mathrm{CpG}$ identifiers to associated entrez-IDs according to Illumina annotation. Then, we used the $R$ Package Pathview [85] for mapping to KEGG pathways. For comparative analyses we grouped samples into three groups with low (Braak stages 0, I, II; average age: 48.3), medium (III, IV; 85) or high (V, VI; 77.9) Braak staging.

\section{Estimation of neuronal cell proportions in brain tissue data} For the estimation of neuronal proportions in tissue data, we used the Houseman et al. surrogate measures of cell mixtures approach. As reference markers, we used the top-ranking $600 \mathrm{CpGs}$ from the comparison (Student's $t$ test) of neuron and glia healthy control samples. Cell proportions were then calculated for each tissue sample with the 'projectCellType' function from the minfi R-software package.

\section{Immunohistochemical staining}

Immunohistochemical staining to assess $\mathrm{AD}$ classification was performed by investigation of up to 25 different brain regions according to the NBM protocols and formalin-fixed and paraffin-embedded. Thereby the extent of neurofibrillary tangle pathology was assessed by immunohistochemical staining of hyperphosphorylated tau (AT8) according to the guidelines published by Braak et al. and classified to stage 0 to VI [13]. Additionally, we performed stainings for DAPI, SORL1 and FOXP1 of occipital cortex regions (BA 17-19). Pictures were made using an Olympus BX50 microscope and a $20 \times$ objective (Olympus, Tokyo, Japan) as well as a Color View III camera (Soft Imaging System, Münster, Germany). We quantified signals from several representative cases where 
FFPE-tissue of target region was available (three pictures for each sample, Additional file 2: Table S3). Statistical evaluation was done using ANOVA and Newman-Keuls post hoc test.

\section{Validation of methylation profiles using NGS}

Validations of 450k results were done by deep sequencing of bisulfite amplicons using a subset of 28 samples. For PCR amplicon design 16 regions were selected (Additional file 2: Table S20). The amplicons were designed to overlap or be located close to CpGs featured on $450 \mathrm{k}$ platform. PCRs were set up in $30 \mu \mathrm{l}$ reactions using $3 \mu \mathrm{l}$ of $10 \times$ Hot Fire Pol Buffer (Solis BioDyne, Tartu, Estonia), $4 \mu \mathrm{l}$ of $10 \mathrm{mM}$ d'NTPs (Fisher Scientific, Pittsburgh, USA), $2.25 \mu \mathrm{l}$ of $25 \mathrm{mM} \mathrm{MgCl} 2$ (Solis BioDyne, Tartu, Estonia), $0.6 \mu \mathrm{l}$ of amplicon specific forward and reverse primer (10 $\mu \mathrm{M}$ each), $0.3 \mu \mathrm{l}$ of Hot FirePol DNA Polymerase (5 U/Ml ; Solis Biodyne, Tartu, Estonia), $1 \mu \mathrm{l}$ of bisulfite DNA and $18.25 \mu \mathrm{l}$ of double distilled water. PCRs were run in an ABI Veriti thermocycler (Life Technologies, Karlsbad, USA) using the following program: $95^{\circ} \mathrm{C}$ for $10 \mathrm{~min}$, then 40 cycles of $95^{\circ} \mathrm{C}$ for $1 \mathrm{~min}, 2.5 \mathrm{~min}$ of $56^{\circ} \mathrm{C}$ and $40 \mathrm{sec}$ at $72^{\circ} \mathrm{C}$, followed by $7 \mathrm{~min}$ of $72{ }^{\circ} \mathrm{C}$ and hold at $4{ }^{\circ} \mathrm{C}$. PCR products were cleaned up using Agencourt AMPure XP Beads (Beckman Coulter, Brea, USA). All amplified products were diluted to $4 \mathrm{nM}$. Next, sequencing adapters compatible to the MiSeq platform (Illumina, San Diego, USA) were attached by PCR: a typical $50 \mu \mathrm{l}$ reaction contained $25 \mu \mathrm{l}$ of the DNA pool, $5 \mu$ l of $10 \times$ HotStartTaq buffer (Qiagen, Hilden, Germany), $4 \mu \mathrm{l}$ of $10 \mathrm{mM}$ d'NTPs, $2 \mu \mathrm{l}$ of $25 \mathrm{mM} \mathrm{MgCl}_{2}, 2.5 \mu \mathrm{l}$ of $10 \mu \mathrm{M}$ universal-primer, $2.5 \mu \mathrm{l}$ of $10 \mu \mathrm{M}$ index-primer (unique for each sample), $0.6 \mu \mathrm{l}$ of HotStartTaq polymerase (Qiagen, Hilden, Germany) and $8.6 \mu \mathrm{l}$ of double distilled water. The reactions were incubated for $15 \mathrm{~min}$ at $97{ }^{\circ} \mathrm{C}$, followed by 5 cycles of $97^{\circ} \mathrm{C}(30 \mathrm{~s}), 60^{\circ} \mathrm{C}(30 \mathrm{~s})$ and $72{ }^{\circ} \mathrm{C}(30 \mathrm{~s})$. After another AMPURE bead-based cleanup step, samples were quantified by a Qubit High Sensitivity Assay (Life Technologies, Karlsbad, USA) and diluted to $10 \mathrm{nM}$. Finally, all samples were pooled and loaded on an Illumina MiSeq sequencing machine. Amplicons were sequenced $2 \times 250$ bp (paired end) involving a MiSeq reagent kit V2 chemistry (Illumina, San Diego, USA). The raw sequencing data was quality checked using FastQC (v0.10.3) and trimmed for adapters and low quality bases using the tools cutadapt (v1.3) and Trim Galore! (v0.3.3). Paired reads were joined using the FLASh tool. Next, reads were sorted in a twostep procedure by (1) the NGS barcode adapters to assign Sample ID and (2) the initial $15 \mathrm{bp}$ to assign amplicon ID. Subsequently, the sorted data was loaded into the BiQAn alyzer HT software 22 using the following settings: the analyzed methylation context was set to 'CG', minimal sequence identity was set to 0.8 and minimal conversion rate was set to 0.95 . The filtered high quality reads were then used for methylation calls of the respective CpGs. For non- $\mathrm{CpG}$ methylation analysis the methylation context was set to " $\mathrm{C}$ " and minimal sequence identity was set to 0.7 .

\section{Public datasets}

Public DNA methylation data from sorted frontal cortex brain samples were downloaded from GEO accession GSE41826 [35]. Only data from 29 Caucasian control donors were used and merged with our own sorted data. Two public brain tissue datasets were downloaded from GEO (GSE59685 [82] and GSE80970 [121]) and-in addition to our own tissue cohort-used for the comparison of sorted and bulk brain tissue data. Data from sorted prefrontal cortex brain samples (NeuN-positive only) under GEO accession GSE98203 [61] were downloaded (fully processed methylation values for 28 healthy control samples) and used for replication of top aging markers in neurons.

\section{Ethics approval and consent to participate}

All procedures performed in studies involving human participants were in accordance with the ethical standards of the institutional and/or national research committee and with the 1964 Helsinki Declaration and its later amendments or comparable ethical standards.

\section{Additional files}

Additional file 1. Supplementary Figures.

Additional file 2. Supplementary Tables.

\section{Abbreviations}

5-caC: 5-carboxymethylcytosine; 5-fC: 5-formylcytosine; 5-hmC: 5-hydroxymethylcytosine; 5-mC: 5-methylcytosine; ACh: acetylcholine; AD: Alzheimer's disease; ADAM17: ADAM metallopeptidase domain 17; ANK1: ankyrin 1; APP. amyloid beta precursor protein; ARSG: arylsulfatase G; BA: Brodmann area; BIN1: bridging integrator 1; CDH23: cadherin-related 23; CERAD: consortium to establish a registry for Alzheimer's disease; CLU: clusterin; CNS: central nervous system; ct: cell-type; CTCF: CCCTC-binding factor; CTRL: control; CUX1: cut like homeobox 1; CXXC5: CXXC finger protein 5; DIP2C: disco-interacting protein 2 homolog C; DMCG: differentially methylated CpG; DNA: deoxy-ribonucleic acid; EC: entorhinal cortex; ELOVL2: fatty acid elongase 2; EWAS: Epigenomewide association study; FACS: fluorescence-activated cell sorting; FAM53B: sequence similarity 53 member $B$; FAM83H: family with sequence similarity 83 member H; FC: frontal cortex; FFPE: formalin-fixed and paraffin-embedded; FHL2: four and a half LIM domains 2; FOXP1: forkhead box P1; GABA: gammaaminobutyric acid; GEO: gene expression omnibus; GNG7: $\mathrm{G}$ protein subunit gamma 7; GO: gene ontology; HDAC4: histone deacetylase 4; HLA-DPB1: major histocompatibility complex, class II, DP beta 1; HOPX: HOP homeobox; HOXA3: homeobox A3; IL1RAPL1: interleukin 1 receptor accessory proteinlike 1; INPP5A: inositol polyphosphate-5-phosphatase A; ITPK1: inositoltetrakisphosphate 1-kinase; KEGG: Kyoto encyclopedia of genes and genomes; LRRC8B: leucine-rich repeat containing 8 VRAC subunit B; MAP2: microtubuleassociated protein 2; MAPK: mitogen-activated protein kinase 1; MBP: myelin basic protein; MCF2L: MCF.2 cell line-derived transforming sequence like; NBM: 
neurobiobank Munich; NCOR2: nuclear receptor corepressor; NeuN: NeuN antigen; NGS: next-generation sequencing; RAl1: retinoid acid induced 1; PAX6: paired box 6; PCA: principal component analysis; PCR: polymerase chain reaction; PSEN1: presenilin 1; PSEN2: presenilin 2; PTPRN2: protein tyrosine phosphatase receptor type N2; RBFOX3: RNA binding Fox-1 homolog 3; RhoA: Ras homolog family member A; ROCK: Rho-associated coiled-coil containing protein; RPL13: ribosomal protein L13; S100B: S100 calcium binding protein B; SEC14L1: SEC14-like lipid binding 1; SORL1: sortilin-related receptor 1; STK32C: serine/threonine kinase 32C; SYNJ2: synaptojanin 2; SYNPO: synaptopodin; TC: temporal cortex; Tet: ten-eleven translocation.

\section{Author's contributions}

GG, JW, HK, MR, HL conceived the experiments. GG, TK conducted laboratory experiments. SB, TK, SS, JV, VD, MS, MH provided help with sample preparation and cell sorting. GG, SB, PL, JW performed data analysis and bioinformatics. HK, MR, AG provided samples for analysis. JW, HL, MR, AG, TA, CM, SR, HK conceived and supervised the project. GG, JW wrote the manuscript. All authors read and approved the final manuscript.

\section{Author details \\ ${ }^{1}$ Department of Genetics, University of Saarland (UdS), Campus, 66123 Saar- brücken, Germany. ${ }^{2}$ Department of Biology and Center for Integrated Protein Science, Ludwig-Maximilians-University (LMU), 82152 Munich, Germany. ${ }^{3}$ Epigenomics and Cancer Risk Factors, German Cancer Research Center (DKFZ), 69120 Heidelberg, Germany. ${ }^{4}$ Center for Neuropathology and Prion Research, Ludwig-Maximilians-University (LMU), 82152 Munich, Germany. ${ }^{5}$ Department of Psychiatry and Psychotherapy, Saarland University Hospital (UKS), 66424 Homburg, Germany.}

\section{Acknowledgements}

This work is dedicated to Hans A. Kretzschmar who initiated this project.

\section{Competing interests}

The authors declare that they have no competing interests.

\section{Availability of data and materials}

Raw and processed microarray data has been deposited in GEO under accession number GSE66351.

\section{Consent for publication}

Not applicable.

\section{Ethics approval and consent to participate}

All procedures performed in studies involving human participants were in accordance with the ethical standards of the institutional and/or national research committee and with the 1964 Helsinki declaration and its later amendments or comparable ethical standards.

\section{Funding}

This work was supported by the German Epigenome Programme (DEEP) of the Federal Ministry of Education and Research in Germany (BMBF) [Grant Numbers $01 \mathrm{KU} 1216 \mathrm{~F}$ to G.G and J.W.]; and by the German Science Society (DFG) [Grant Number SFB 1064 A17/22 to H.L. and S.B.].

\section{Publisher's Note}

Springer Nature remains neutral with regard to jurisdictional claims in published maps and institutional affiliations.

\section{Received: 30 April 2018 Accepted: 17 July 2018}

Published online: 25 July 2018

\section{References}

1. Aryee MJ, Jaffe AE, Corrada-Bravo H, Ladd-Acosta C, Feinberg AP, Hansen KD, Irizarry RA. Minfi: a flexible and comprehensive bioconductor package for the analysis of infinium dna methylation microarrays. Bioinformatics. 2014;30(10):1363-9.

2. Attems J, Jellinger KA. Amyloid and tau: neither chicken nor egg but two partners in crime!. Acta Neuropathol. 2013;126(4):619.
3. Austoker J, Cox D, Mathias AP. Fractionation of nuclei from brain by zonal centrifugation and a study of the ribonucleic acid polymerase activity in the various classes of nuclei. Biochem J. 1972;129(5):1139-55.

4. Baker-Nigh A, Vahedi S, Davis EG, Weintraub S, Bigio EH, Klein WL, Geula C. Neuronal amyloid- $\beta$ accumulation within cholinergic basal forebrain in ageing and alzheimer's disease. Brain. 2015;138(6):1722-37.

5. Bakulski KM, Dolinoy DC, Sartor MA, Paulson HL, Konen JR, Lieberman AP, Albin RL, Hu H, Rozek LS. Genome-wide dna methylation differences between late-onset alzheimer's disease and cognitively normal controls in human frontal cortex. J Alzheimers Dis. 2012;29(3):571-88.

6. Barrachina $M$, Ferrer I. Dna methylation of alzheimer disease and tauopathy-related genes in postmortem brain. J Neuropathol Exp Neurol. 2009;68(8):880-91.

7. Bates D, Mächler M, Bolker B, Walker S. Fitting linear mixed-effects models using Ime4. J Stat Softw. 2015;67(1):1-48.

8. Beet M, Stravalaci M, Romeo M, Carrá AD, Cagnotto A, Rossi A, Diomede $L$, Salmona M, Gobbi M. Clusterin binds to a $\beta 1-42$ oligomers with high affinity and interferes with peptide aggregation by inhibiting primary and secondary nucleation. J Biol Chem. 2016;291(13):6958-66.

9. Bekaert B, Kamalandua A, Zapico SC, Van de Voorde W, Decorte R. Improved age determination of blood and teeth samples using a selected set of dna methylation markers. Epigenetics. 2015;10(10):922-30.

10. Bhatia N, Hall G. Untangling the role of tau in alzheimer's disease: a unifying hypothesis. Transl Neurosci. 2013;4(2):115-33.

11. Bonacini M, Coletta M, Ramazzina I, Naponelli V, Modernelli A, Davalli P, Bettuzzi S, Rizzi F. Distinct promoters, subjected to epigenetic regulation, drive the expression of two clusterin mrnas in prostate cancer cells. Biochim Biophys Acta (BBA) Gene Regul Mech. 2015;1849(1):44-54.

12. Braak H, Braak E. On areas of transition between entorhinal allocortex and temporal isocortex in the human brain. normal morphology and lamina-specific pathology in alzheimer's disease. Acta Neuropathol. 1985;68(4):325-32.

13. Braak H, Alafuzoff I, Arzberger T, Kretzschmar H, Del Tredici K. Staging of alzheimer disease-associated neurofibrillary pathology using paraffin sections and immunocytochemistry. Acta Neuropathol. 2006;112(4):389-404.

14. Bradley-Whitman MA, Lovell MA. Epigenetic changes in the progression of Alzheimer's disease. Mech Ageing Dev. 2013;134(10):486-95.

15. Buxbaum JD, Liu K-N, Luo Y, Slack JL, Stocking KL, Peschon JJ, Johnson RS, Castner BJ, Cerretti DP, Black RA. Evidence that tumor necrosis factor $\alpha$ converting enzyme is involved in regulated $\alpha$-secretase cleavage of the alzheimer amyloid protein precursor. J Biol Chem. 1998;273(43):27765-7.

16. Cacace R, Sleegers K, Van Broeckhoven C. Molecular genetics of early-onset Alzheimer's disease revisited. Alzheimer's Dement. 2016;12(6):733-48.

17. Canobbio I, Visconte C, Oliviero B, Guidetti G, Zara M, Pula G, Torti M. Increased platelet adhesion and thrombus formation in a mouse model of Alzheimer's disease. Cell Signal. 2016;28(12):1863-71.

18. Chen H, Dzitoyeva S, Manev H. Effect of aging on 5-hydroxymethylcytosine in the mouse hippocampus. Restor Neurol Neurosci. 2012;30(3):237-45.

19. Coppieters N, Dieriks BV, Lill C, Faull RLM, Curtis MA, Dragunow M. Global changes in dna methylation and hydroxymethylation in alzheimer's disease human brain. Neurobiol Aging. 2014;35(6):1334-44.

20. Cortellino S, Xu J, Sannai M, Moore R, Caretti E, Cigliano A, Le Coz M, Devarajan K, Wessels A, Soprano D, et al. Thymine dna glycosylase is essential for active dna demethylation by linked deamination-base excision repair. Cell. 2011;146(1):67-79.

21. Cunin P, Beauvillain C, Miot C, Augusto J-F, Preisser L, Simon Blanchard P, Pignon MS, Garo E, Fremaux I, et al. Clusterin facilitates apoptotic cell clearance and prevents apoptotic cell-induced autoimmune responses. Cell Death Dis. 2016;7(5):e2215.

22. Cuyvers E, Sleegers K. Genetic variations underlying alzheimer's disease: evidence from genome-wide association studies and beyond. Lancet Neurol. 2016;15(8):857-68.

23. Czech C, Tremp G, Pradier L. Presenilins and alzheimer's disease: biological functions and pathogenic mechanisms. Prog Neurobiol. 2000;60(4):363-84. 
24. Danielson PE, Watson JB, Gerendasy DD, Erlander MG, Lovenberg TW, Lecea L, Sutcliffe JG, Frankel WN. Chromosomal mapping of mouse genes expressed selectively within the central nervous system. Genomics. 1994;19(3):454-61.

25. David M, Mann A, Hardy J. Amyloid or tau: the chicken or the egg? Acta Neuropathol. 2013;126(4):609.

26. Davies MN, Volta M, Pidsley R, Lunnon K, Dixit A, Lovestone S, Cristian Coarfa R, Harris A, Milosavljevic A, Troakes C, et al. Functional annotation of the human brain methylome identifies tissue-specific epigenetic variation across brain and blood. Genome Biol. 2012;13(6):R43.

27. De Jager PL, Srivastava G, Lunnon K, Burgess J, Schalkwyk LC, Yu L, Eaton ML, Keenan BT, Ernst J, McCabe C, Tang A, Raj T, Replogle J, Brodeur W, Gabriel S, Chai HS, Younkin C, Younkin SG, Zou F, Szyf M, Epstein CB, Schneider JA, Bernstein BE, Meissner A, Ertekin-Taner N, Chibnik LB, Kellis M, Mill J, Bennett DA. Alzheimer's disease: early alterations in brain DNA methylation at ANK1, BIN1, RHBDF2 and other loci. Nat Neurosci. 2014;17(9):1156-63.

28. Deb M, Sengupta D, Rath SK, Kar S, Parbin S, Shilpi A, Pradhan N, Bhutia SK, Roy S, Patra SK. Clusterin gene is predominantly regulated by histone modifications in human colon cancer and ectopic expression of the nuclear isoform induces cell death. Biochim Biophys Acta (BBA) Mol Basis Dis. 2015;1852(8):1630-45.

29. Del Turco D, Schlaudraff J, Bonin M, Deller T. Upregulation of app, adam 10 and adam 17 in the denervated mouse dentate gyrus. PLoS One. 2014;9(1):e84962.

30. Deming Y, Li Z, Kapoor M, Harari O, Del-Aguila JL, Black K, Carrell D, Cai Y, Victoria Fernandez M, Budde J, et al. Genome-wide association study identifies four novel loci associated with Alzheimer's endophenotypes and disease modifiers. Acta Neuropathologica. 2017;133(5):839-56.

31. Finch NCA, Wang X, Baker MC, Heckman MG, Gendron TF, Bieniek KF, Wuu J, DeJesus-Hernandez M, Brown PH, Chew J, et al. Abnormal expression of homeobox genes and transthyretin in c9orf72 expansion carriers. Neurol Genet. 2017;3(4):e161.

32. Francis PT. The interplay of neurotransmitters in Alzheimer's disease. CNS Spectr. 2005;10(S18):6-9.

33. Florent G, Lim S, Hoeffel G, Low D, Huber T. Origin and differentiation of microglia. Front Cell Neurosci. 2013;7:45.

34. Gross JA, Pacis A, Chen GG, Barreiro LB, Ernst C, Turecki G. Characterizing 5-hydroxymethylcytosine in human prefrontal cortex at single base resolution. BMC Genom. 2015;16(1):672.

35. Guintivano J, Aryee MJ, Kaminsky ZA. A cell epigenotype specific model for the correction of brain cellular heterogeneity bias and its application to age, brain region and major depression. Epigenetics. 2013:8(3):290-302.

36. Habib N, Li Y, Heidenreich M, Swiech L, Avraham-Davidi I, Trombetta JJ, Hession C, Zhang F, Regev A. Div-seq: single-nucleus rna-seq reveals dynamics of rare adult newborn neurons. Science. 2016;353(6302):925-8.

37. Hamby ME, Coppola G, Ao Y, Geschwind DH, Khakh BS, Sofroniew MV. Inflammatory mediators alter the astrocyte transcriptome and calcium signaling elicited by multiple g-protein-coupled receptors. J Neurosci. 2012;32(42):14489-510.

38. Hansson E, Rönnbäck L, Persson LI, Lowenthal A, Noppe M, Alling C, Karlsson B. Cellular composition of primary cultures from cerebral cortex, striatum, hippocampus, brainstem and cerebellum. Brain Res. 1984;300(1):9-18.

39. Hardy JA, Higgins GA. Alzheimer's disease: the amyloid cascade hypothesis. Science. 1992;256(5054):184.

40. Harold D, Abraham R, Hollingworth P, Sims R, Gerrish A, Hamshere ML, Pahwa JS, Moskvina V, Dowzell K, Williams A, et al. Genome-wide association study identifies variants at clu and picalm associated with Alzheimer's disease. Nat Genet. 2009;41(10):1088-93.

41. Hayashi T, Yoshida T, Ra M, Taguchi R, Mishina M. II1 rapl1 associated with mental retardation and autism regulates the formation and stabilization of glutamatergic synapses of cortical neurons through rhoa signaling pathway. PLoS One. 2013;8(6):e66254.

42. He Y-F, Li B-Z, Li Z, Liu P, Wang Y, Tang Q, Ding J, Jia Y, Chen Z, Li L, et al. Tet-mediated formation of 5-carboxylcytosine and its excision by tdg in mammalian dna. Science. 2011;333(6047):1303-7.

43. Hernandez DG, Nalls MA, Raphael Gibbs J, Arepalli S, van der Brug M, Chong S, Moore M, Longo DL, Cookson MR, Traynor BJ, et al. Distinct dna methylation changes highly correlated with chronological age in the human brain. Hum Mol Genet. 2011;20(6):1164-72.

44. Herrup K. The case for rejecting the amyloid cascade hypothesis. Nat Neurosci. 2015;18(6):794-9.

45. Hoss AG, Kartha VK, Dong X, Latourelle JC, Dumitriu A, Hadzi TC, MacDonald ME, Gusella JF, Akbarian S, Chen J-F, et al. Micrornas located in the hox gene clusters are implicated in huntington's disease pathogenesis. PLoS Genet. 2014;10(2):e1004188.

46. Houseman AE, Kile ML, Christiani DC, Ince TA, Kelsey KT, Marsit CJ. Reference-free deconvolution of dna methylation data and mediation by cell composition effects. BMC Bioinf. 2016;17(1):259.

47. Houseman AE, Accomando WP, Koestler DC, Christensen BC, Marsit CJ, Nelson HH, Wiencke JK, Kelsey KT. Dna methylation arrays as surrogate measures of cell mixture distribution. BMC Bioinf. 2012;13(1):86.

48. Houseman EA, Molitor J, Marsit CJ. Reference-free cell mixture adjustments in analysis of dna methylation data. Bioinformatics. 2014;30(10):1431-9.

49. Huang Y, Pastor WA, Shen Y, Tahiliani M, Liu DR, Rao A. The behaviour of 5-hydroxymethylcytosine in bisulfite sequencing. PLOS One. 2010;5(1):e8888.

50. Hyman BT, Phelps CH, Beach TG, Bigio EH, Cairns NJ, Carrillo MC, Dickson DW, Duyckaerts C, Frosch MP, Masliah E, et al. National institute on aging-Alzheimer's association guidelines for the neuropathologic assessment of Alzheimer's disease. Alzheimer's Dement. 2012;8(1):1-13.

51. Iwamoto K, Bundo M, Ueda J, Oldham MC, Ukai W, Hashimoto E, Saito T, Geschwind DH, Kato T. Neurons show distinctive dna methylation profile and higher interindividual variations compared with non-neurons. Genome Res. 2011;21(5):688-96.

52. Iwata A, Nagata K, Hatsuta H, Takuma H, Bundo M, Iwamoto K, Tamaoka A, Murayama S, Saido T, Tsuji S. Altered cpg methylation in sporadic Alzheimer's disease is associated with app and mapt dysregulation. Hum Mol Genet. 2013;23(3):648-56.

53. Jack CR, Knopman DS, Jagust WJ, Shaw LM, Aisen PS, Weiner MW Petersen RC. Hypothetical model of dynamic biomarkers of the Alzheimer's pathological cascade. Lancet Neurol. 2010;9(1):119-28.

54. Jepsen K, Solum D, Zhou T, McEvilly RJ, Kim H-J, Glass CK, Hermanson O, Rosenfeld MG. Smrt-mediated repression of an h3k27 demethylase in progression from neural stem cell to neuron. Nature. 2007;450(7168):415

55. Jiang Y, Matevossian A, Huang H-S, Straubhaar J, Akbarian S. Isolation of neuronal chromatin from brain tissue. BMC Neurosci. 2008;9(1):42.

56. Jin S-G, Kadam S, Pfeifer GP. Examination of the specificity of dna methylation profiling techniques towards 5-methylcytosine and 5-hydroxymethylcytosine. Nucleic Acids Res. 2010;38(11):e125.

57. Johnson EW, Li C, Rabinovic A. Adjusting batch effects in microarray expression data using empirical bayes methods. Biostatistics. 2007;8(1):118-27.

58. Jung M, Pfeifer GP. Aging and dna methylation. BMC Biol. 2015;13(1):7.

59. Kananen L, Marttila S, Nevalainen T, Jylhävä J, Mononen N, Kähönen M, Raitakari OT, Lehtimäki T, Hurme M. Aging-associated dna methylation changes in middle-aged individuals: the young finns study. BMC Genom. 2016;17(1):103.

60. Kizil C, Küchler B, Yan J-J, Özhan G, Moro E, Argenton F, Brand M, Weidinger $G$, Antos CL. Simplet/fam53b is required for wnt signal transduction by regulating $\beta$-catenin nuclear localization. Development. 2014;141(18):3529-39.

61. Kozlenkov A, Jaffe AE, Timashpolsky A, Apontes P, Rudchenko S, Barbu M, Byne W, Hurd YL, Horvath S, Dracheva S. Dna methylation profiling of human prefrontal cortex neurons in heroin users shows significant difference between genomic contexts of hyper-and hypomethylation and y younger epigenetic age. Genes. 2017;8(6):152.

62. Kozlenkov A, Wang M, Roussos P, Rudchenko S, Barbu M, Bibikova M, Klotzle B, Dwork AJ, Zhang B, Hurd YL, et al. Substantial dna methylation differences between two major neuronal subtypes in human brain. Nucl Acids Res. 2015;44(6):2593-612.

63. Kraus TFJ, Kilinc S, Steinmaurer M, Stieglitz M, Guibourt V, Kretzschmar HA. Profiling of methylation and demethylation pathways during brain development and ageing. J Neural Transm. 2016;123(3):189-203.

64. Kriaucionis S, Heintz N. The nuclear dna base 5-hydroxymethylcytosine is present in purkinje neurons and the brain. Science. 2009;324(5929):929-30. 
65. Kurscheid S, Bady P, Sciuscio D, Samarzija I, Shay T, Vassallo I, Criekinge WV, Daniel RT, van den Bent MJ, Marosi C, et al. Chromosome 7 gain and dna hypermethylation at the hoxa10 locus are associated with expression of a stem cell related hox-signature in glioblastoma. Genome Biol. 2015;16(1):16.

66. Labadorf A, Hoss AG, Lagomarsino V, Latourelle JC, Hadzi TC, Bregu J, MacDonald ME, Gusella JF, Chen J-F, Akbarian S, et al. Rna sequence analysis of human huntington disease brain reveals an extensive increase in inflammatory and developmental gene expression. PLoS One. 2015;10(12):e0143563.

67. Lacour A, Espinosa A, Louwersheimer E, Heilmann S, Hernández I, Wolfsgruber S, Fernández V, Wagner H, Rosende-Roca M, Mauleón A, et al. Genome-wide significant risk factors for alzheimer's disease: role in progression to dementia due to alzheimer's disease among subjects with mild cognitive impairment. Mol Psychiatry. 2017;22(1):153.

68. Lahiri DK, Maloney B, Zawia NH. The learn model: an epigenetic explanation for idiopathic neurobiological diseases. Mol Psychiatry. 2009:14(11):992-1003.

69. Lambert J-C, Ibrahim-Verbaas CA, Harold D, Naj AC, Sims R, Bellenguez C, Jun G, DeStefano AL, Bis JC, Beecham GW, et al. Meta-analysis of 74,046 individuals identifies 11 new susceptibility loci for Alzheimer's disease. Nat Genet. 2013;45(12):1452-8.

70. Lashley T, Gami P, Valizadeh N, Li A, Revesz T, Balazs R. Alterations in global dna methylation and hydroxymethylation are not detected in alzheimer's disease. Neuropathol Appl Neurobiol. 2015;41(4):497-506.

71. Leek JT, Johnson WE, Parker HS, Fertig EJ, Jaffe AE, Storey JD. SVA: Surrogate Variable Analysis. R package version 3.12.0

72. Lehne B, Drong AW, Loh M, Zhang W, Scott WR, Tan S-T, Afzal U, Scott $J$, Jarvelin M-R, Elliott P, et al. A coherent approach for analysis of the illumina humanmethylation 450 beadchip improves data quality and performance in epigenome-wide association studies. Genome Biol. 2015;16(1):37.

73. Leskov KS, Araki S, Lavik J-P, Gomez JA, Gama V, Gonos ES, Trougakos IP, Matsuyama S, Boothman DA. Crm1 protein-mediated regulation of nuclear clusterin (nCLU), an ionizing radiation-stimulated, bax-dependent pro-death factor. J Biol Chem. 2011;286(46):40083-90.

74. Ling I-F, Bhongsatiern J, Simpson JF, Fardo DW, Estus S. Genetics of clusterin isoform expression and Alzheimer's disease risk. PLoS One. 2012;74:e33923.

75. Lister R, Mukamel EA, Nery JR, Urich M, Puddifoot CA, Johnson ND, Lucero J, Huang Y, Dwork AJ, Schultz MD, et al. Global epigenomic reconfiguration during mammalian brain development. Science. 2013;341(6146):1237905.

76. Lister R, Pelizzola M, Dowen RH, David Hawkins R, Hon G, Tonti-Filippini J, Nery JR, Lee L, Ye Z, Ngo Q-M, et al. Human dna methylomes at base resolution show widespread epigenomic differences. Nature. 2009:462(7271):315-22.

77. Littlefield A, Kohman RA. Differential response to intrahippocampal interleukin-4/interleukin-13 in aged and exercise mice. Neuroscience. 2017;343:106-14.

78. Liu S, Cui B, Dai Z, Shi P, Wang Z, Guo Y. Long non-coding rna hotair promotes parkinson's disease induced by mptp through up-regulating the expression of Irrk2. Curr Neurovasc Res. 2016;13(2):115-20.

79. Lizen B, Hutlet B, Bissen D, Sauvegarde D, Hermant M, Ahn M-T, Gofflot F. Hoxa5 localization in postnatal and adult mouse brain is suggestive of regulatory roles in postmitotic neurons. J Comp Neurol. 2017:525(5):1155-75.

80. Løvtrup-Rein $\mathrm{H}, \mathrm{McEwen} B S$. Isolation and fractionation of rat brain nuclei. J Cell Biol. 1966;30(2):405

81. LuY, He X, Zhong S. Cross-species microarray analysis with the oscar system suggests an insr-> pax6-> nqo1 neuro-protective pathway in aging and Alzheimer's disease. Nucl Acids Res. 2007;35(suppl_2):W105-W114.

82. Lunnon K, Smith R, Hannon E, De Jager PL, Srivastava G, Volta M Troakes C, Al-Sarraj S, Burrage J, Macdonald R, Condliffe D, Harries LW, Katsel P, Haroutunian V, Kaminsky Z, Joachim C, Powell J, Lovestone S, Bennett DA, Schalkwyk LC, Mill J. Methylomic profiling implicates cortical deregulation of ANK1 in Alzheimer's disease. Nat Neurosci. 2014:17(9):1164-70

83. Lunnon K, Hannon E, Smith RG, Dempster E, Wong C, Burrage J, Troakes C, Al-Sarraj S, Kepa A, Schalkwyk L, et al. Variation in 5-hydroxymethylcytosine across human cortex and cerebellum. Genome Biol. 2016;17(1):27.

84. Luo C, Keown CL, Kurihara L, Zhou J, He Y, Li J, Castanon R, Lucero J, Nery JR, Sandoval JP, et al. Single-cell methylomes identify neuronal subtypes and regulatory elements in mammalian cortex. Science. 2017;357(6351):600-4

85. Luo W, Brouwer C. Pathview: an r/bioconductor package for pathway-based data integration and visualization. Bioinformatics. 2013:29(14):1830-1.

86. Lutsik P, Slawski M, Gasparoni G, Vedeneev N, Hein M, Walter J. Medecom: discovery and quantification of latent components of heterogeneous methylomes. Genome Biol. 2017;18(1):55.

87. Lutter D, Ullrich F, Lueck JC, Kempa S, Jentsch TJ. Selective transport of neurotransmitters and modulators by distinct volume-regulated Irrc8 anion channels. J Cell Sci. 2017;130(6):1122-33.

88. Maloney B, Lahiri DK. Epigenetics of dementia: understanding the disease as a transformation rather than a state. Lancet Neurol. 2016;15(7):760-74.

89. Maloney B, Sambamurti K, Zawia N, Lahiri DK. Applying epigenetics to alzheimer's disease via the latent early-life associated regulation (learn) model. Curr Alzheimer Res. 2012;9:589-99.

90. Mann DM, Yates PO. Neurotransmitter deficits in alzheimer's disease and in other dementing disorders. Human neurobiology. 1986:5(3):147-58

91. Manzanares M, Bel-Vialar S, Ariza-McNaughton L, Ferretti E, Marshall H, Maconochie MM, Blasi F, Krumlauf R. Independent regulation of initiation and maintenance phases of hoxa3 expression in the vertebrate hindbrain involve auto-and cross-regulatory mechanisms. Development. 2001;128(18):3595-607.

92. Mastroeni D, Sekar S, Nolz J, Delvaux E, Lunnon K, Mill J, Liang WS, Coleman PD. Ank1 is up-regulated in laser captured microglia in alzheimer's brain; the importance of addressing cellular heterogeneity. PLoS One. 2017;12(7):e0177814.

93. Matevossian A, Akbarian S. Neuronal nuclei isolation from human postmortem brain tissue. JoVE J Vis Exp. 2008;20:e914.

94. Miners JS, Clarke P, Love S. Clusterin levels are increased in Alzheimer's disease and influence the regional distribution of a $\beta$. Brain Pathol. 2010;42:15-6

95. Morris CJ, Mohs RC, Rogers H, Fillenbaum G, Heyman A. Consortium to establish a registry for alzheimer's disease (cerad) clinical and neuropsychological assessment of alzheimer's disease. Psychopharmacol Bull. 1987:24(4):641-52.

96. Mundel P, Heid HW, Mundel TM, Krüger M, Reiser J, Kriz W. Synaptopodin: an actin-associated protein in telencephalic dendrites and renal podocytes. J Cell Biol. 1997;139(1):193-204.

97. Newman AM, Liu CL, Green MR, Gentles AJ, Feng W, Xu Y, Hoang CD, Diehn M, Alizadeh AA. Robust enumeration of cell subsets from tissue expression profiles. Nat Methods. 2015;12(5):453-7.

98. Numata S, Ye T, Hyde TM, Guitart-Navarro X, Tao R, Wininger M, Colantuoni C, Weinberger DR, Kleinman JE, Lipska BK. Dna methylation signatures in development and aging of the human prefrontal cortex. Am J Hum Genet. 2012;90(2):260-72.

99. Parikh V, Bernard CS, Naughton SX, Yegla B. Interactions between a $\beta$ oligomers and presynaptic cholinergic signaling. Behav Brain Res. 2014:274:30-42.

100. PEARSON EC, BATES DL, PROSPERO TD, THOMAS JO. Neuronal nuclei and glial nuclei from mammalian cerebral cortex. Eur J Biochem. 1984;144(2):353-60

101. Philippidou P, Dasen JS. Hox genes: choreographers in neural development, architects of circuit organization. Neuron. 2013;80(1):12-34.

102. Phipps AJ, Vickers JC, Taberlay PC, Woodhouse A. Neurofilament-labeled pyramidal neurons and astrocytes are deficient in dna methylation marks in alzheimer's disease. Neurobiol Aging. 2016;45:30-42.

103. Qian $M$, Shen $X$, Wang H. The distinct role of adam 17 in app proteolysis and microglial activation related to alzheimer's disease. Cell Mol Neurobiol. 2016;36(4):471-82.

104. Rahmani E, Zaitlen N, Baran Y, Eng C, Donglei H, Galanter J, Sam O, Burchard EG, Eskin E, Zou J, et al. Sparse pca corrects for cell type heterogeneity in epigenome-wide association studies. Nat Methods. 2016;13(5):443-5. 
105. Rahmani E, Zaitlen N, Baran Y, Eng C, Donglei H, Galanter J, Sam O, Burchard EG, Eskin E, Zou J, et al. Correcting for cell-type heterogeneity in dna methylation: a comprehensive evaluation. Nat Methods. 2017;14(3):218-9.

106. Rauhala HE, Porkka KP, Saramäki OR, Tammela TLJ, Visakorpi T. Clusterin is epigenetically regulated in prostate cancer. Int J Cancer. 2008;123(7):1601-9.

107. Reisetter AC, Muehlbauer MJ, Bain JR, Nodzenski M, Stevens RD, Ilkayeva O, Metzger BE, Newgard CB, Lowe WL, Scholtens DM. Mixture model normalization for non-targeted gas chromatography/mass spectrometry metabolomics data. BMC Bioinf. 2017;18(1):84.

108. Ribeiro FM, Ferreira LT, Marion S, Fontes S, Gomez M, Ferguson SSG, Prado MAM, Prado VF. Sec14-like protein 1 interacts with cholinergic transporters. Neurochem Int. 2007;50(2):356-64.

109. Rizzardi L, Hickey P, Rodriguez V, Tryggvadottir R, Callahan C, Idrizi A, Hansen K, Feinberg AP. Neuronal brain region-specific dna methylation and chromatin accessibility are associated with neuropsychiatric disease heritability. bioRxiv 2017

110. Roshchupkin GV, Adams HH, van der Lee SJ, Vernooij MW, van Duijn CM, Uitterlinden AG, van der Lugt A, Hofman A, Niessen WJ, Ikram MA. Fine-mapping the effects of Alzheimer's disease risk loci on brain morphology. Neurobiol Aging. 2016:48:204-11.

111. Ruzicka WB, Subburaju S, Benes FM. Variability of dna methylation within schizophrenia risk loci across subregions of human hippocampus. Genes. 2017;8(5):143.

112. Sasaki K, Omotuyi OI, Ueda M, Shinohara K, Ueda H. Nmda receptor agonists reverse impaired psychomotor and cognitive functions associated with hippocampal hbegf-deficiency in mice. Mol brain. 2015;8(1):83.

113. Schliebs R, Arendt T. The cholinergic system in aging and neuronal degeneration. Behav Brain Res. 2011;221 (2):555-63.

114. Schwindinger WF, Mirshahi UL, Baylor KA, Sheridan KM, Stauffer AM, Usefof S, Stecker MM, Mirshahi T, Robishaw JD. Synergistic roles for g-protein $\gamma 3$ and $\gamma 7$ subtypes in seizure susceptibility as revealed in double knock-out mice. J Biol Chem. 2012;287(10):7121-33.

115. Selkoe DJ. The molecular pathology of alzheimer's disease. Neuron. 1991;6(4):487-98.

116. Selkoe DJ. Alzheimer's disease is a synaptic failure. Science. 2002;298(5594):789-91.

117. Selkoe DJ. Preventing alzheimer's disease. Science. 2012;337(6101):1488-92.

118. Sen P, Shah PP, Nativio R, Berger SL. Epigenetic mechanisms of longevity and aging. Cell. 2016;166(4):822-39.

119. Sims R, van der Lee SJ, Naj AC, Bellenguez C, Badarinarayan N, Jakobsdottir J, Kunkle BW, Boland A, Raybould R, Bis JC, et al. Rare coding variants in PLCG2, ABI3, and TREM2 implicate microglial-mediated innate immunity in Alzheimer's disease. Nat Genet. 2017;49(9):1373.

120. Skovronsky DM, Fath S, Lee VM-Y, Milla ME. Neuronal localization of the tnf $\alpha$ converting enzyme (tace) in brain tissue and its correlation to amyloid plaques. Dev Neurobiol. 2001;49(1):40-6.

121. Smith RG, Hannon E, De Jager PL, Chibnik L, Lott SJ, Condliffe D, Smith AR, Haroutunian V, Troakes C, Al-Sarraj S, et al. Elevated DNA methylation across a 48-kb region spanning the HOXA gene cluster is associated with Alzheimer's disease neuropathology. Alzheimer's Dement. 2018. https://doi.org/10.1016/j.jalz.2018.01.017.

122. Soreq L, Rose J, Soreq E, Hardy J, Trabzuni D, Cookson MR, Smith C, Ryten M, Patani R, Ule J, et al. Major shifts in glial regional identity are a transcriptional hallmark of human brain aging. Cell Rep. 2017;18(2):557-70.

123. Steegenga WT, Boekschoten MV, Lute C, Hooiveld GJ, De Groot PJ Morris TJ, Teschendorff AE, Butcher LM, Beck S, Müller M. Genomewide age-related changes in dna methylation and gene expression in human pbmcs. Age. 2014;36(3):9648.

124. Tahiliani M, Koh KP, Shen Y, Pastor WA, Bandukwala H, Brudno Y, Agarwa S, lyer LM, Liu DR, Aravind L, et al. Conversion of 5-methylcytosine to 5 -hydroxymethylcytosine in mammalian dna by mll partner tet1. Science. 2009;324(5929):930-5.

125. Tamura S, Morikawa Y, Iwanishi H, Hisaoka T, Senba E. Expression pattern of the winged-helix/forkhead transcription factor foxp1 in the developing central nervous system. Gene Expr Patterns. 2003;3(2):193-7.

126. Thal DR, Rüb U, Orantes $M$, Braak H. Phases of $a \beta$-deposition in the human brain and its relevance for the development of ad. Neurology. 2002:58(12):1791-800

127. Theiler J. Combining statistical tests by multiplying $p$-values. Astrophysics and Radiation Measurements Group, NIS-2, 2004.

128. Thompson RJ. Studies on rna synthesis in two populations of nuclei from the mammalian cerebral cortex. J Neurochem. 1973;21(1):19-40.

129. Tohgi H, Utsugisawa K, Nagane Y, Yoshimura M, Genda Y, Ukitsu M. Reduction with age in methylcytosine in the promoter region- 224-101 of the amyloid precursor protein gene in autopsy human cortex. Mol Brain Res. 1999;70(2):288-92.

130. Trougakos IP, Gonos ES. Functional analysis of clusterin/apolipoprotein $\mathrm{j}$ in cellular death induced by severe genotoxic stress. Ann NY Acad Sci. 2004;1019(1):206-10

131. Trougakos IP, Lourda M, Agiostratidou G, Kletsas D, Gonos ES. Differential effects of clusterin/apolipoprotein $j$ on cellular growth and survival. Free Radical Biol Med. 2005;38(4):436-49.

132. Violette SM, Shashikant CS, Salbaum JM, Belting H-G, Wang JC, Ruddle $\mathrm{FH}$. Repression of the beta-amyloid gene in a hox-3.1-producing cell line. Proc Nat Acad Sci. 1992:89(9):3805-9.

133. Vostrov AA, Quitschke WW. The zinc finger protein ctcf binds to the $\operatorname{apb} \beta$ domain of the amyloid $\beta$-protein precursor promoter evidence for a role in transcriptional activation. J Biol Chem. 1997;272(52):33353-9.

134. Vostrov AA, Taheny MJ, Quitschke WW. A region to the $\mathrm{n}$-terminal side of the ctcf zinc finger domain is essential for activating transcription from the amyloid precursor protein promoter. J Biol Chem. 2002:277(2):1619-27.

135. Watson C, Leanage G, Makki N, Tvrdik P. Escapees from rhombomeric lineage restriction-extensive migration rostral to the $r 4 / \mathrm{r} 5$ border of HOX-a3 expression. The Anatomical Record, 2017.

136. Wen L, Li X, Yan L, Tan Y, Li R, Zhao Y, Wang Y, Xie J, Zhang Y, Song C, et al. Whole-genome analysis of 5-hydroxymethylcytosine and 5-methylcytosine at base resolution in the human brain. Genome Biol. 2014;15(3):R49.

137. West RL, Lee JM, Maroun LE. Hypomethylation of the amyloid precursor protein gene in the brain of an Alzheimer's disease patient. J Mol Neurosci. 1995;6(2):141-6

138. Wojtas AM, Kang SS, Olley BM, Gatherer M, Shinohara M, Lozano PA, Liu C-C, Kurti A, Baker KE, Dickson DW, et al. Loss of clusterin shifts amyloid deposition to the cerebrovasculature via disruption of perivascular drainage pathways. In: Proceedings of the National Academy of Sciences, 2017:201701137.

139. Wu F, Zhang C, Cai J, Yang F, Liang T, Yan X, Wang H, Wang W, Chen $\mathrm{J}$, Jiang T. Upregulation of long noncoding rna hoxa-as 3 promotes tumor progression and predicts poor prognosis in glioma. Oncotarget. 2017:8(32):53110

140. Yang G, Haihong Zhang Y, Liu JZ, He W, Quick CM, Xie D, Smoller BR, Fan C-Y. Epigenetic and immunohistochemical characterization of the clusterin gene in ovarian tumors. Arch Gynecol Obstet. 2013;287(5):989-95.

141. Yang X, Li J, Liu B, Li Y, Jiang T. Impact of picalm and clu on hippocampal degeneration. Hum Brain Mapp. 2016;37(7):2419-30.

142. Yang Y, Quitschke W, Vostrov AA, Brewer GJ. Ctcf is essential for upregulating expression from the amyloid precursor protein promoter during differentiation of primary hippocampal neurons. J Neurochem. 1999;73(6):2286-98

143. Ye Q, Su F, Shu H, Gong L, Xie C-M, Zhou H, Zhang Z-J, Bai F. Shared effects of the clusterin gene on the default mode network among individuals at risk for Alzheimer's disease. CNS Neurosci Ther. 2017;23(5):395-404

144. Zheng SC, Beck S, Jaffe AE, Koestler DC, Hansen KD, Houseman AE, Irizarry RA, Teschendorff AE. Correcting for cell-type heterogeneity in epigenome-wide association studies: revisiting previous analyses. Nat Methods. 2017;14(3):216-7.

145. Zhou Y, Hayashi I, Wong J, Tugusheva K, Renger JJ, Zerbinatti C. Intracellular clusterin interacts with brain isoforms of the bridging integrator 1 and with the microtubule-associated protein tau in alzheimer's disease. PLoS One. 2014;9(7):e103187. 